\title{
Bacterial Secretion Systems with an Emphasis on the Chlamydial Type III Secretion System
}

\author{
Delphine Sylvie Anne Beeckman ${ }^{*}$ and Daisy C.G. Vanrompay
}

Department of Molecular Biotechnology, Faculty of Bioscience Engineering, Ghent University, Coupure Links 653, BE-9000 Ghent, Belgium

*Corresponding author: Delphine.Beeckman@UGent.be

\begin{abstract}
Numerous bacterial proteins exert their function outside the prokaryotic cell. To this end, both Gram-negative and Gram-positive bacteria have evolved specialized mechanisms to transport their proteins to the bacterial supernatant or host cell cytoplasm, so called secretion systems. These different strategies will be briefly discussed, followed by an in depth description of the Type III secretion system, an efficient molecular syringe assisting Gram-negative bacteria in entrance, growth and survival in eukaryotic host cells. Topics addressed include classification and role of multiple Type III secretion systems, the mechanism of protein translocation into the host cell as well as substrate recognition and chaperoning.

Chlamydiales have also been found to encode a Type III secretion system and associated effector proteins. In contrast to the genetic organization in other bacteria, the encoding genes are scattered throughout the genome. To date, no structural information is available on the chlamydial Type III secretion system. We therefore propose a model of the chlamydial Type III secretion system and summarize current knowledge on the role of Type III secretion in the different stages of the chlamydial developmental cycle.
\end{abstract}

\section{Bacterial secretion systems Introduction}

Bacterial pathogens have evolved numerous strategies to efficiently infect and colonize their eukaryotic hosts. Most often, secreted or surface-exposed bacterial proteins play central roles in the interaction of these pathogens with their host cells, mediating diverse processes such as proteolysis, hemolysis, cytotoxicity and phosporylation or dephosphorylation of host cell proteins (Hueck, 1998). In order to fulfil their function they have to be transported from the bacterial cytoplasm to the supernatant or the bacterial surface, a process which is called secretion. In Gram-negative bacteria, the barrier to be crossed consists of an inner and an outer membrane, separated by the periplasmic space. Often, Sec or Tat systems transport unfolded and/or folded proteins first to the periplasmic space (export, see further), where they are processed (e.g. addition of disulphide bridges) to obtain their final three-dimensional structure, before being transported across the outer membrane. Translocation refers to the transport of proteins directly across the eukaryotic cell membrane into the host cell cytoplasm where they can interfere with cellular processes and suppress host defences (Buttner and Bonas, 2002). In addition, transport through the outer membrane requires ATP or other sources of energy, no indications of which exist that they are present at the outer membrane. Secretion systems must therefore be self-energized or harness energy at the cytoplasmic side of the inner membrane.

Until recently, six major pathways by which these proteins are transported from the bacterial cytoplasm to the extracellular space had been identified (Thanassi and Hultgren, 2000), four of which depend on the 'general secretory pathway' (GSP or Sec pathway): Type II and Type IV secretion, autotransporters (Type V secretion) and the chaperone/usher pathway. These Sec-dependent pathways export proteins with a short amino terminal signal sequence ( 30 amino acids) through the inner membrane to the periplasmic space, where the largely hydrophobic signal sequence is cleaved off by a peptidase (Hueck, 1998; Thanassi and Hultgren, 2000). Alternatively, Type II secretion can also be Tat-dependent: proteins are targeted across the inner membrane in their fully folded conformation, by an amino terminal signal peptide containing two arginine residues (Panahandeh et al., 2009). Type I and Type III secretion do not depend on the Sec system to fulfil their function. Although first described in 1996, another protein secretion mechanism was recognized in 2006 as being the Type VI secretion mechanism (Mougous et al., 2006; Pukatzki et al., 2006). Figure 1 gives an overview of these seven major secretion mechanisms, which will be discussed briefly, except the Type III secretion system. Since Type III secretion is the main focus of this review, it will be described in more detail further on.

\section{Protein export to the periplasm}

Two parallel pathways for the export of proteins across the inner membrane are described in prokaryotes: the Sec-dependent pathway and the Tat (twin-arginine translocation) pathway. Both systems can deliver their substrates to the Type II secretion pathway.

Sec-dependent protein export

The Sec-pathway is evolutionarily conserved among bacteria, archaea and eukaryotes, mediating export of proteins across the bacterial inner membrane or endoplasmic reticulum (Stephenson, 2005). All Secexported proteins contain an amino terminal signal peptide ( 30 mainly hydrophobic amino acids) targeting 
them to the membrane embedded SecYEG translocon, serving as a polypeptide conducting channel, through which no tightly folded preproteins can pass. Premature folding of a preprotein is avoided by interaction with specific targeting factors: 1) in the SRP pathway, SRP targets the preprotein to the translocon (adjacent to an SRP receptor) while still in its nascent, ribosome associated state, followed by integration in the lipid bilayer (co-translational targeting); 2) the other is the SecB pathway, with chaperone SecB binding to the full-length translated preprotein, targeting the protein to the SecASecYEG pore. Subsequently, the preprotein is exported for secretion in the periplasm (Ito and Mori, 2009). This post-translational mode of export is driven by the SecA ATPase, generating energy from ATP hydrolysis and the proton-motive force. The signal peptide is usually cleaved off on the periplasmic side by a signal peptidase (SPI), encoded by lepB in $E$. coli, releasing the mature protein into the periplasmic space (Rusch and Kendall, 2007). Certain archaeal Sec signal sequences contain a lipobox motif ([I/L/G/A]-[A/G/S]-C), ensuring recognition by the type II signal peptidase (SPII), and anchoring of the mature lipoprotein to the cytoplasmic or outer membrane (Pohlschröder and Dilks, 2007).

Twin-arginine translocation pathway

The twin-arginine translocation pathway is found in bacteria, archaea and eukaryotes to transport proteins into or across the bacterial inner membrane (Berks et al., 2000; Wu et al., 2000) or across the chloroplast thylakoid membrane (Settles et al., 1997). Contrary to the Sec-pathway, proteins of variable dimensions are exported in their fully folded conformation across the cytoplasmic membrane, without rendering the membrane freely permeable to protons and other ions. Bacterial proteins are targeted to the Tat pathway by an amino terminal signal peptide containing an almost invariant twin-arginine sequence motif, SRRxFLK, where $\mathrm{x}$ is a polar amino acid, while Tat signals in chloroplasts are more variable (Panahandeh et al., 2009). The Tat pathway not only delivers proteins to the periplasm, but also allows integration of inner membrane proteins in e.g. E. coli (Hatzixanthis et al., 2003), Paracoccus denitrificans (Bachmann et al., 2006) and Legionella pneumophila (De Buck et al., 2007). The Tat translocase of $E$. coli consists of the membrane proteins TatA, TatB, and TatC (Sargent et al., 1998). The transmembrane TatBC complex binds Tat secretion substrates with TatC recognizing the precursor protein consensus signal peptide, followed by proton motive force dependent recruitment of TatA to form a fully assembled and functional Tat translocase. After export of the passenger domain across the membrane, without compromising the membrane potential, the TatABC complex dissociates again and the signal peptide is cleaved off by periplasmic signal peptidases (Panahandeh et al., 2009).

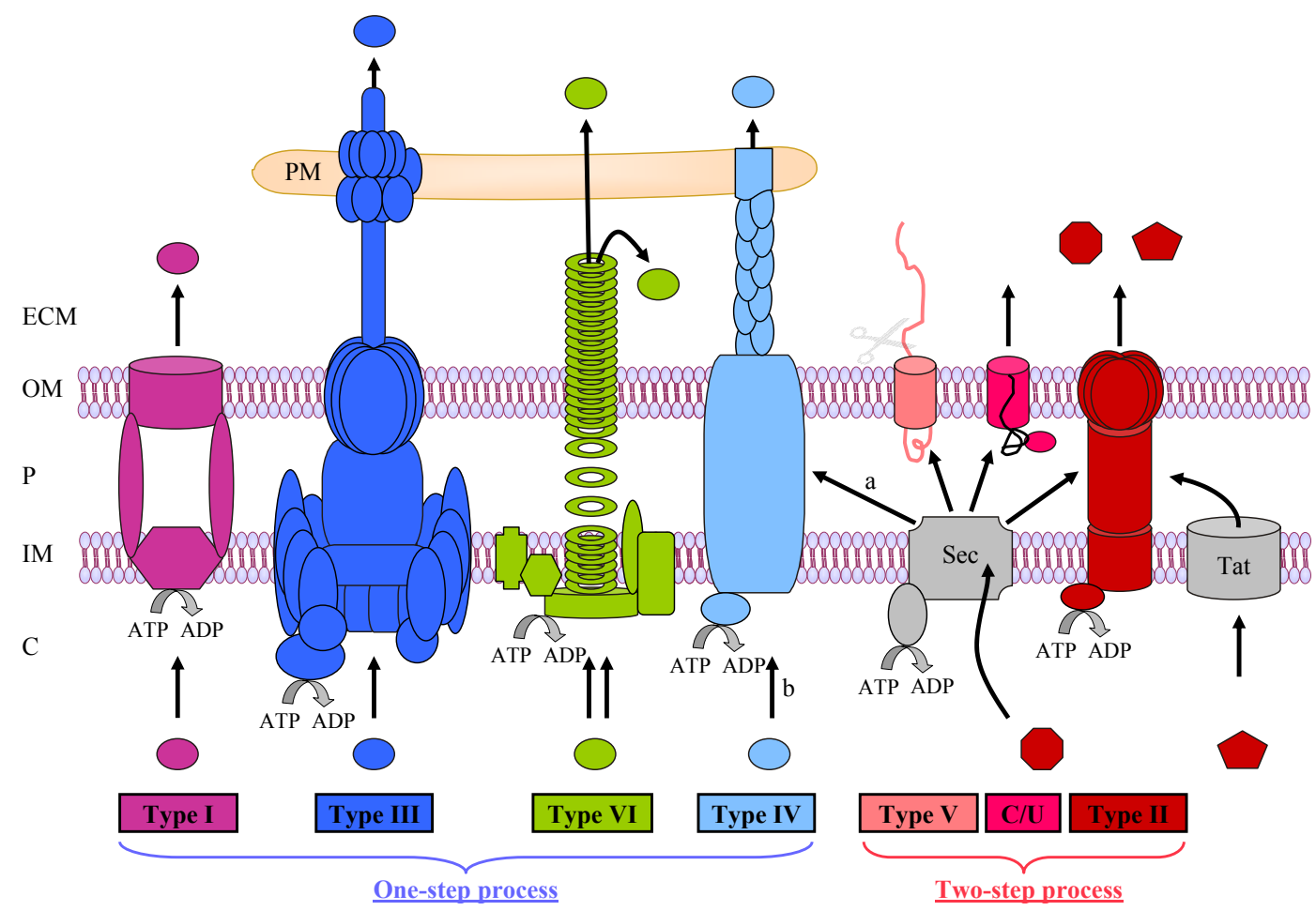

Figure 1: Major protein-secretion systems in Gram-negative bacteria. Four of these protein secretion pathways of depend on the Sec system for protein transport across the inner membrane. Type I, III and VI secretion are Sec-independent. Type I secretion systems predominantly secrete toxins, proteases and lipases into the extracellular milieu, whereas Type III secretion systems also translocate virulence proteins into the host cell. Type VI secretion mediated by a novel kind of a complex multi-component secretion machine, is often involved in interaction with eukaryotic hosts. Type IV secretion systems mediate the transport of DNA and proteins across the double membrane to bacterial or eukaryotic cells, requiring direct cell-to-cell contact. Examples are the Bordetella pertussis toxin (Sec-dependent, a) or the Agrobacterium tumefaciens VirB/D4 sytem for transport of T-DNA-protein complexes (Sec-independent, b). Autotransporters form a pore through the outer membrane and are therefore classified among the Type $\mathbf{V}$ secretion systems. The chaperone/usher pathway $(\mathrm{C} / \mathrm{U})$ consists of an OM protein, termed an usher, and a periplasmic chaperone, guiding proper folding and preventing premature interactions. Complexes of 12-16 proteins mediate transport of extracellular enzymes and toxins in Type II secretion: a pilus-like structure of four IM proteins pushes the proteins, delivered to the periplasm by the Sec or Tat system, through an OM pore.

Legend: C, bacterial cytoplasm; IM, bacterial inner membrane; P, bacterial periplasm; OM, bacterial outer membrane; ECM, extracellular milieu. PM, host cell plasma membrane. When appropriate, coupling of ATP hydrolysis to transport is highlighted. Arrows indicate the route followed by transported proteins. Adapted from Buttner and Bonas (2002) and Filloux et al. (2008). 
Type I secretion system

Type I secretion systems (T1SSs), also known as ATPbinding cassette $(A B C)$ transporters, are used by a vast number of Gram-negative bacteria for the secretion of various molecules, ranging from ions and drugs to proteins. Substrates include toxins (leukotoxine of Pasteurella haemolytica and hemolysin A of E. coli), proteases (metalloproteases of Pseudomonas aeruginosa and Erwinia chrysanthemi), hemophores (hemoproteins of Serratia marcescens and Pseudomonas aeruginosa) and lipases (Serratia marcescens LipA). An overview of substrates for the T1SS can be found in Jenewein et al. (2009). The secreted molecules vary in size from the small $E$. coli peptide colicin V of $10 \mathrm{kDa}$ (Gilson et al., 1990) to the Pseudomonas fluorescens cell adhesion protein LapA of $900 \mathrm{kDa}$ (Hinsa et al., 2003). Type I secretion is also involved in export of non-proteinaceous substrates like cyclic $\beta$-glucans and polysaccharides (Jenewein et al., 2009). Both in eukaryotic and prokaryotic organisms, related $A B C$ transporters are conserved, transporting different toxins and antibiotics (Andersen, 2003).

In Gram-negative bacteria, Type I secretion is carried out by a translocator made up of three proteins that span the cell envelope: an inner membrane ATPase (the actual ABC transporter), a specific outer membrane protein (OMP, exported through the Sec-pathway) and the so-called membrane fusion or adaptor protein (MFP), connected in the inner membrane and spanning the periplasmic space. The $A B C$ protein ensures that only T1SS specific substrates are recognized via a carboxy terminal secretion signal, whereafter MFP binds the substrate on the cytoplasmic side. The MFP also links the inner membrane components to the OMP, forming a pore in the outer membrane. The secretion signal, mostly rich in the glycine-repeated motif GGxGxD, located within the carboxy terminal 50-60 amino acids, is specific for the different subfamilies of the T1SS. Type I secretion is Sec-independent and secretes the protein directly to the extracellular medium, without cleavage of the signal peptide (Delepelaire, 2004; Jenewein et al., 2009).

\section{Type I/ secretion system}

Type II secretion systems (T2SSs) are widely conserved and common, but by no means universal, among Gramnegative bacteria ( $\alpha-, \beta-, \gamma-, \delta$ - and $\varepsilon$-Proteobacteria). Predominantly extracellular toxins and hydrolytic enzymes (e.g. cellulases, elastases, amylases, proteases, phosphatases, lipases, nucleases,...) are secreted by the T2SS of bacterial pathogens of plants (Pseudomonas fluorescens, Erwinia spp., Xanthomonas spp.), animals (Aeromonas hydrophila) and humans (Klebsiella oxytoca, Pseudomonas aeruginosa, Legionella pneumophila), as recently reviewed by Cianciotto (2005) and Michel and Voulhoux (2009). Before the discovery of the Tat pathway, the T2SS was regarded as the 'main terminal branch of the general secretory pathway', extending the Sec export pathway. This led to confusion when 'general secretory pathway' was also used to describe the whole process of Secdependent export followed by Type II secretion (T2S). With the Tat pathway appearing in the discussion, it was proposed to reserve the designation 'GSP' to describe the Sec-pathway, while retaining the name 'T2SS' to describe a two-step process where the protein is first exported into the periplasmic space via a translocase (Sec or Tat, Table 1) and subsequently transported across the outer membrane by a dedicated secretion apparatus called the 'secreton' (Desvaux et al., 2004b). The signal sequence in cleaved off by a periplasmic peptidase, thus releasing the mature protein.

The secreton, spanning the periplasm and connecting the inner and outer bacterial membranes is encoded by a cluster of 12 to 16 gsp genes, depending on the species. Peabody et al. (2003) noticed that some bacteria seem to have a significant, but incomplete, number of T2S core proteins (e.g. Aquifex aeolicus encodes gspDEFGO, Thermotoga maritima gspDEFG, and Chlamydiaceae harbor gspCDEFG), which was confirmed by Cianciotto (2005). Further research is needed to determine whether these T2S homologs encode a functional secreton.

Exoproteins that use the T2SS are characterized by the presence of a leader peptide (or signal peptide) at their $\mathrm{N}$ terminus. The T2SS is unique in its ability to secrete large multimeric proteins that are folded in the periplasm and species specificity is mainly related to the gatekeeper proteins GspC and GspD (Michel and Voulhoux, 2009). GspG, H, I and J encode pseudopilins, pushing the substrate through GspD in the outer membrane. GspE contains a conserved ATP binding motif and exhibits autokinase activity, thus providing energy and regulating the whole secretion process (Thanassi and Hultgren, 2000).

At least four constituents of the T2SS (GspE, F, D and O) share homology with components of Type IV pili (T4P) of Pseudomonas aeruginosa and other bacteria (Hueck, 1998; Peabody et al., 2003) and of DNA transfer systems of e.g. Haemophilus influenzae and Bacillus subtilis [reviewed in Averhoff and Friedrich (2003)]. The T2S homologs identified in some bacteria might therefore also function in piliation or DNA uptake.

Recently, a novel protein targeting system was identified in Dickeya dadantii, formerly classified as Erwinia chrysanthemi. A pectin lyase, $\mathrm{PnIH}$, contains a wellconserved Tat signal sequence, but lacks any obvious signal peptidase cleavage site, and thus is not processed in the periplasmic space. Subsequently, the protein is targeted to the outer membrane by a novel T2SS, where it remains localized on the surface of the cell, probably because the uncleaved amino terminal Tat signal acts as an outer membrane anchor. The authors hypothize that this is likely to be a general mechanism as $E$. coli was able to successfully integrate proteins bearing the $D$. dadantii signal peptide into its own outer membrane. This second T2SS is encoded on a cluster of 11 stt (second type two) genes, all of which share homology to the standard T2SS, and its substrate $p n I H$ is encoded immediately downstream of this stt cluster (Ferrandez and Condemine, 2008).

Type IV secretion system

Type IV secretion systems (T4SSs) are macromolecular nanomachines which transport macromolecules (proteins, DNA or DNA-protein complexes) across the bacterial cell envelope of Gram-negative and Grampositive bacteria into the extracellular milieu or directly into recipient cells. They can be classified according to sequence homology into 1) T4SSs related to the 
archetypal Agrobacterium tumefaciens VirB/D4 mechanism (Type IVA), 2) Legionella (L.) pneumophila Dot/Icm related T4SSs (Type IVB, some of which are classified as Type VI secretion, described further on) and 3) other T4SS not yet fully characterized. Alternatively, a classification according to function can be made: 1) conjugative transfer of plasmids and other mobile DNA elements to recipient bacteria, 2) delivery of protein or substrates to eukaryotic target cells ('effector translocator' systems), 3) exchange of DNA substrates with the extracellular milieu ('DNA release or uptake systems') or 4) exclusive transport of proteins to the exterior medium or directly into recipient cells [reviewed in Christie et al. (2005) and Baron (2009)].

The best studied model of a T4SS is the T-DNA transfer system of Agrobacterium tumefaciens. It comprises 12 proteins named VirB1 through 11 and VirD4. VirB4, VirB11 and VirD4 contain conserved Walker A nucleotide-binding/hydrolysis motifs, energizing the assembly of the T4SS and/or substrate translocation. However, VirD4 appears to function as a general receptor for DNA and protein, operating independently from ATP energy (Christie and Cascales, 2005). Core components VirB6, VirB7, VirB8, VirB9 and VirB10 likely form the translocation channel, while the T-pilus is built up by VirB2 and VirB5, the major and minor surface-exposed pilus subunits, respectively. These pili mediate cell-to-cell contact and substrate translocation, but it is unclear whether substrates actually move through the pili (Baron, 2005; 2009).
Only limited information is available regarding protein secretion by the T4SS. In Helicobacter pylori, CagA is translocated through the T4SS to the host cells where it induces disruption of cell-to-cell junctions, actin cytoskeletal rearrangement as well as proliferative, proinflammatory and anti-apoptotic nuclear responses (Brandt et al., 2005; Backert and Selbach, 2008). Bordetella pertussis toxin (Ptx), involved in whooping cough, is also secreted through a T4SS, but instead of directly entering a target cell like most other effector proteins, it is secreted into the extracellular medium. Ptx is composed of five different protein subunits (S1-S5), which are first exported into the bacterial periplasm by the Sec-pathway (Table 1). After cleavage of the signal peptides, components assemble to form the holotoxin, followed by extracellular secretion. Once secreted, Ptx alone mediates host cell binding and delivery of its catalytic S1 subunit into the host cytosol. Thus, protein secretion and host cell translocation of the effector are not linked in this particular T4SS (Rambow-Larsen and Weiss, 2004). The L. pneumophila Type IVB SS (Dot/lcm) is known to deliver proteins into target cells, e.g. RalF required for the localization of ARF (ADPribosylation factor) on phagosomes containing $L$. pneumophila (Nagai et al., 2002).

T4SSs in other bacteria can display additional components or have homologs for only a subset of those proteins described in this section. A recent review on the topic is published by Baron (2009).

Table 1: Protein export, secretion and translocation systems in bacteria. $\mathrm{G}^{-}$, Gram-negative; $\mathrm{G}^{+}$, Gram-positive. Adapted from Economou et al. (2006).

\begin{tabular}{|c|c|c|c|c|c|}
\hline Name & Process & Sec/Tat dependence $^{a}$ & $\mathrm{G}^{-}$ & $\mathrm{G}^{+}$ & Remarks \\
\hline Sec (SRP-SecB) & Export & NA & Yes & Yes & \\
\hline Tat & Export & NA & Yes & Yes & \\
\hline T1SS & Secretion & No & Yes & Yes & Generally small substrates in $\mathrm{G}^{+}$ \\
\hline T2SS & Secretion & Yes & Yes & No & \\
\hline T3SS & Translocation & No & Yes & No & \\
\hline Flagellum & Secretion & No & Yes & No & Equivalent to T3SS \\
\hline T4SS & Translocation & Variable & Yes & Yes & Conjugation system \\
\hline T4P & Secretion & Yes & Yes & Yes & Equivalent to T2SS \\
\hline T5SS & Secretion & Yes & Yes & No & \\
\hline T6SS & Translocation & No & Yes & No & \\
\hline $\mathrm{C} / \mathrm{U}$ & Secretion & Yes & Yes & No & Assembly of pili and fimbriae \\
\hline
\end{tabular}

${ }^{a}$ For translocated protein; assembly of machinery does require Sec NA: not applicable

Type V secretion systems: autotransporters and twopartner secretion

Type V secretion systems (T5SSs) are present in a wide range of Gram-negative bacteria for secretion of large virulence proteins across the outer membrane. Until now, three families have been recognized: the autotransporter (AT) system (Type $\mathbf{V}_{a}$ or AT-1), the two-partner secretion pathway (Type $\mathbf{V}_{\mathbf{b}}$ ), and the more recently described Type $\mathbf{V}_{\mathbf{c}}$ system (also termed AT-2) (Desvaux et al., 2004a). Proteins secreted via these pathways have similarities in their primary structures as well as striking similarities in their modes of biogenesis. Shared characteristics include: 1) an amino terminal signal sequence for inner membrane export via the Sec machinery (Table 1), 2) a functional passenger domain that can be surface-exposed or released into the extracellular milieu, 3) a linker region necessary for translocation of the passenger domain through the outer membrane, 4) a carboxy terminal region involved in the formation of a transmembrane pore. Once through the inner membrane, the signal sequence is cleaved and a $\beta$-domain inserts into the outer membrane to form a $\beta$-barrel pore. The passenger domain is then translocated to the bacterial cell surface via the pore, where it may or may not undergo further processing. This process is assisted by an internal autochaperone sequence in the passenger domain (Henderson et al., 2004; Scott-Tucker and Henderson, 2009). However, recent studies reveal the probable 
involvement of accessory proteins such as periplasmic chaperones and BamA OM protein as well [overview in Scott-Tucker and Henderson (2009)].

The autotransporters are most prevalent in the phylum Proteobacteria, including the $\alpha-, \beta-, \quad \gamma^{-}$and $\varepsilon$ Proteobacteria. Other phyla in which autotransporters have also been identified are Chlamydiae, genera Chlamydia (C.) and Chlamydophila (Cp.) (Henderson and Lam, 2001) and Fusobacteria (Desvaux et al., 2005). The chlamydial polymorphic membrane proteins or pmps contain the necessary Sec signal sequence for export through the inner membrane and can be divided into at least six subtypes based on phylogenetic analysis (Henderson and Lam, 2001). Although specific roles in pathogenesis have been described for some pmps [reviewed in Tan et al. (2006)], a role in the avoidance of the host immune response as already earlier proposed by Tanzer et al. (2001), is highly probable.

Whether or not the autotransporter pathway is energydependent is highly debated. Neither ATP nor GTP is present in the periplasm, so hydrolysis of these molecules cannot provide the energy for translocation of the passenger domain through the outer membrane and no evidence exists for a proton motive force across the outer membrane. It has been suggested that release of the auto-chaperone or folding of the $\beta$-barrel or passenger domain might provide the required energy [overview in Henderson et al. (2004)].

The autotransporter pathway differs from the two-partner secretion pathway in the fact that, instead of being produced as a single polypeptide, the passenger domain and the pore forming $\beta$-domain are translated as two separate proteins, referred to as TpsA (also called the exoprotein) and TpsB (also called transporter domain) family members, respectively. The genes encoding these two proteins are usually organized in an operon. Specific secretion signals are present in a highly conserved region of the secretion domain of TpsA. In addition to its channel function, TpsB probably also serves as a specific receptor of the TpsA signal peptide (Jacob-Dubuisson et al., 2001). Characteristic examples of autotransporters and the two-partner secretion pathway respectively are the $\lg \mathrm{A} 1$ proteases of Neisseria spp. (Pohlner et al., 1987) and the $220 \mathrm{kDa}$ filamentous hemaglutinin of Bordetella spp. (JacobDubuisson et al., 2001).

The AT-2 pathway is very similar to the classical autotransporters, but contains a remarkably short carboxy terminal translocator domain. Hence, three AT-2 polypeptides are required to form a functional $\beta$-barrel pore, which also functions as an adhesin of various bacteria (e.g. Hia of Haemophilus influenza, YadA of Yersinia (Y.) enterocolitica and UspA of Moraxella catharralis) (Scott-Tucker and Henderson, 2009).

\section{Type VI secretion systems}

Although only named Type VI secretion system (T6SS) in 2006 (Pukatzki et al., 2006), indications on the presence of T6SSs date from a decade earlier, with Hcp (haemolysin co-regulated protein) from Vibrio cholerae shown to be secreted without cleavage of a signal peptide. In the years that followed, similar mechanisms were described in Rhizobium leguminosarum, Pseudomonas aeruginosa and L. pneumophila. Das and Chaudhuri named the encoding gene clusters IAHP, for
'IcmF-associated homologous proteins', because they contain a gene encoding a homolog of the IcmF protein associated with Type IVB secretion in L. pneumophila (Das and Chaudhuri, 2003). This gene cluster is conserved among Gram-negative bacteria but the majority of proteins encoded have no homology to T4SSs or any other known secretion system components (Bingle et al., 2008). So far, in silico analysis has proven the existence of one or two T6SS clusters in more than 100 bacterial species, but a few species, including Burkholderia spp., can contain up to six clusters. Whether these multiple systems represent a redundancy for virulence or specificities for particular niches or hosts is still unclear. Core components conserved among all T6SSs include the T4SS IcmF- and IcmH-like proteins, a putative lipoprotein, the ClvP AAA+ ATPase (possibly providing the energy) and the Hcp and VgrG (valine-glycine repeats) proteins (Cascales, 2008). The presence of a functional T6SS in distinct bacterial isolates is often associated with the ability to induce host diseases or disorders. In the past three years, several functions have been attributed to translocated T6SS effector proteins, including adhesion to and invasion of the host cell and promoting intracellular growth within macrophages or survival and persistence within the host. These and other subversions of host cell functions (e.g. signaling cascades, inflammatory responses, intracellular trafficking,...) are elegantly summarized in Cascales (2008).

\section{Chaperone/usher pathway}

The chaperone/usher $(\mathrm{C} / \mathrm{U})$ pathway is implicated in the assembly and secretion of a superfamily of virulenceassociated surface structures in Gram-negative bacteria (Thanassi et al., 1998). Only two proteins are required to mediate transport through the outer membrane: a periplasmic chaperone protein and an integral outer membrane protein termed usher. Typical structures assembled on the outer membrane through the $\mathrm{C} / \mathrm{U}$ pathway are rigid, rod-like fibres, termed pili or fimbriae, but amorphous capsular and thin fibrillar structures have also been observed (Thanassi et al., 2009). C/U pathways are subdivided into six major phylogenetic groups, termed $\alpha-, \beta-, \gamma_{-}, \mathrm{K}-, \pi$-, and $\sigma$-fimbriae (Nuccio and Baumler, 2007). The prototypes of the $C / U$ pathway are the adhesive Type 1 and $\mathrm{P}$ pili of uropathogenic $E$. coli (Abraham et al., 1988; Marklund et al., 1992). These pili are composite structures built from multiple subunit proteins, which are first exported to the periplasmic space via the Sec system (Table 1). In the periplasm, the chaperones bind to the subunits through a conserved carboxy terminal motif, allowing cleavage of the amino terminal Sec signal peptide. This way, correct folding is ensured and premature interactions between the pili subunits are prevented. The chaperone-subunit complexes are then targeted to a dimeric usher in the outer membrane, each containing a central $\beta$-barrel channel domain. Interaction of a first complex with one of both ushers, induces dissociation of the chaperone and opening of the usher channel $(2-3 \mathrm{~nm})$ allowing the subunit to pass. A second chaperone-subunit complex binds to the second usher in a similar way, and both subunits interact at the bacterial cell surface. Repetition of the whole process (which is energy-independent) allows extension of the pilus and twisting of the pili rod 
into its final helical conformation (Thanassi et al., 2005; 2009).

An alternative $\mathrm{C} / \mathrm{U}$ pathway exists, exhibiting the same function as the classical C/U pathway, but displaying low sequence homology. It is found primarily in enterotoxigenic E. coli (ETEC) strains (Li et al., 2007).

\section{Type III secretion system}

\section{Introduction}

Unlike Type I and Type II secretion systems, secreting active proteins in the bacterial supernatant, Type III secretion systems (T3SSs) predominantly translocate proteins to the cytoplasm of eukaryotic host cells (Hueck, 1998). Factors inducing protein secretion include contact with the surface of the target cell ('contact dependent secretion', cds) and environmental factors such as a shift in temperature to $37^{\circ} \mathrm{C}$, a change in extracellular $\mathrm{pH}$ or iron concentration and depletion of calcium ions to millimolar concentrations. An overview of these phenomena can be found in Ramamurthi and Schneewind (2002).

The T3SS is by far the most complex of protein secretion systems known today: it is composed of approximately 25 proteins, predominantly localized in the cell envelope, spanning both the bacterial inner and outer membrane as well as the plasma membrane of the eukaryotic cell when actively translocating effector proteins (Plano et al., 2001). Most inner membrane structures are homologous to components of the 'flagellar basal body' in both Gram-negative and Gram-positive bacteria (Kubori et al., 1998; Macnab, 1999). The secretin SctC, localized in the outer membrane shows homology to PulD, the outer membrane secreton of the T2SS (Hueck, 1998). Genes coding for the structural components and translocated effectors are mostly clustered in a single pathogenicity island (PAI) on a plasmid or within the bacterial chromosome, leading to the assumption that these clusters are inherited as a single unit (Plano et al., 2001). Although the structural components of T3SSs are generally conserved, the actual arsenal of bacterial proteins that they deliver (collectively known as 'effectors' or T3SEs) is unique to each system (Galan and Wolf-Watz, 2006). Most of these effector proteins require cytoplasmic chaperones to protect the secreted substrates from premature interactions with the other components of the T3SS (Hueck, 1998). The whole process is energized by a cytoplasmic, inner membrane associated ATPase (Akeda and Galan, 2004).

Type III protein translocation is independent of the Secpathway and no periplasmic intermediate is generated through amino terminal processing, similar to Type I and Type VI secretion. However, several structural components of the T3SS do harbor the typical amino terminal Sec signal peptide, indicating that the Secpathway is probably involved in T3SS assembly (Hueck, 1998).

\section{The T3SS is not necessarily a virulence hallmark ...}

Since it was first described in Yersinia less than twenty years ago (Michiels et al., 1990), T3SSs to translocate specialized proteins to the cytoplasm of a eukaryotic host cell or the lumen of an intracellular organelle have been identified in numerous Gram-negative bacteria, especially Proteobacteria, but so far, none were found in $\varepsilon$-Proteobacteria. The following list aims to give an overview but is far from complete, as with the increasing number of bacterial genomes being sequenced, more bacterial species with T3SSs will be identified. The T3SSs are best characterized in bacteria infecting mammals, e.g. Yersinia spp., Salmonella spp., Chlamydia and Chlamydophila spp., Shigella spp., Pseudomonas aeruginosa, enterohemorrhagic (EHEC) and enteropathogenic (EPEC) E. coli, Bordetella spp., Burkholderia spp., Edwarsiella tarda, Citrobacter rodentium and Chromobacterium violaceum (Hueck, 1998; Pallen et al., 2003a; Brito et al., 2004; Cornelis, 2006). Pathogens infecting fish, such as Aeromonas salmonicida subsp. salmonicida, Aeromonas hydrophila, Vibrio parahaemolyticus and Yersinia ruckeri also deploy T3SSs as a virulence determinant (Burr et al., 2003; Gunasena et al., 2003; Makino et al., 2003a; Pallen et al., 2003a), as is also the case for plant pathogens Xanthomonas spp., Erwinia spp., Pseudomonas spp. and Ralstonia solanacearum (Hueck, 1998; Pallen et al., 2003a). However, not only pathogens harbor a T3SS: Rhizobium spp. (soil bacteria, nitrogen fixation in plants), Sodalis glossinidius (tse-tse fly Glossina spp. symbiont) and SZPE (Sitophilus zeamais primary endosymbiont, in grain weevils) and other endosymbionts also possess a T3SS (Dale et al., 2001; 2002; Marie et al., 2001). Genome sequencing of the Protochlamydia (P.) amoebophila UWE25 symbiont of amoeba revealed genes encoding a complete T3SS as well as effector proteins (Horn et al., 2004) as is the case for commensals, such as non-pathogenic $E$. coli strains (Pallen et al., 2003a) or mutualists, e.g. Photorhabdus luminescens in entomophagous nematodes (Cornelis, 2006).

\section{Role of multiple T3SSs in the same cell}

In some bacteria, multiple T3SS encoding gene clusters are present. In Salmonella (S.) enterica, PAls SPI-1 and SPI-2 code for two different T3SSs, inv/spa and spi/ssa, respectively (Hensel et al., 1995) and both systems depend on a common post-translational isomerase (Pallen et al., 2005). Likewise, three Yersinia-species ( $Y$. pestis, $Y$. pseudotuberculosis and $Y$. enterocolitica) harbor, apart from a well-characterized plasmid encoded Ysc-Yop system, a chromosomally encoded T3SS (Ysa, SPI-2 like), which although degenerate is important in Yersinia virulence (Haller et al., 2000). Moreover, crosstalk and functional overlap between both systems have been demonstrated (Young and Young, 2002). In the case of Vibrio parahaemolyticus, a ubiquitous chromosome-1 T3SS is implicated in cytotoxicity, whereas the chromosome-2 encoded system, only present in strains pathogenic to humans, mediates enterotoxicity (Park et al., 2004). Most commensal and pathogenic $E$. coli strains also encode two T3SSs, the second being SPI-1 like (Makino et al., 2003b; Ren et al., 2004). Burkholderia pseudomallei and related species can harbor up to three T3SSs: two systems, TTS1 and TTS2, are homologous to T3SSs of plant pathogens and a third system (TTS3 or Bsa) is similar to SPI-1 of S. enterica. Fascinatingly, the TTS1, which is similar to T3SSs found in plant pathogens, appears to be restricted to $B$. pseudomallei strains that are pathogenic to humans (Rainbow et al., 2002; Stevens et al., 2002). 
As a relationship between $B$. pseudomallei and plants has already been proposed (Mahfouz et al., 2006), its TTS1 may allow this human pathogen to infect plants as well.

A possible reason for the presence of multiple T3SSs is that the different systems function at different stages of the infection. This has already been established for Salmonella, where the major function of the SPI-1 T3SS is to enable invasion of epithelial cells in the early stage of infection, while the SPI-2 T3SS is required to allow replication inside macrophages. Subsequently, the bacteria can spread throughout the body and induce a systemic infection. Thus, the two T3SSs, each with its specific set of regulators and effectors, are needed during different periods of infection [reviewed in Schlumberger and Hardt (2006)].

A similar phenomenon occurs in Chlamydiaceae. Instead of possessing two separate T3SSs, only the components that are built into the plasma membrane of the eukaryotic cell (translocators CopB and CopD) and their specific chaperone are encoded twice by the genome. It is believed that CopB1 and CopD1 are required for translocation of effectors mediating internalization of the pathogen, while CopB2 and CopD2 are built into the inclusion membrane, to allow transport of effectors reprogramming the host cell functions to maintain intracellular growth (Ouellette et al., 2005; Hefty and Stephens, 2007).

\section{Different families of T3SSs}

As already mentioned in the introduction, structural components and translocated effectors are often clustered on elements with a high plasticity (plasmids or PAls). Phylogenetic analysis on their amino acid sequences reveals the existence of at least seven different clades or families of related T3SSs: Ysc-Yop, SPI-1 (Inv-Mxi-Spa), SPI-2 (Ssa-Esc), Hrc1 (Hrp1) and Hrc2 (Hrp2) in plant pathogens, Chlamydiales (Sct) and Rhizobiales (Gophna et al., 2003; Pallen et al., 2005; Troisfontaines and Cornelis, 2005), each with their specific nomenclature (Table 2). Carrying out the analysis on different constituents of the T3SS generates the same tree, whatever the component used for computing (Gophna et al., 2003) and (Troisfontaines and Cornelis, 2005).

This indicates that all of the genes encoding T3SSs have evolved as large, intact genetic blocks. Within each of the seven families, genetic organization of the loci is identical (syntheny). The most striking feature of this evolutionary tree is that it is completely different from the bacterial evolutionary tree based on 16S rRNA (Gupta, 2000), implying that Type III secretion has been distributed among bacteria through horizontal gene transfer. For bacteria with multiple T3SSs, the corresponding proteins in each T3SS are xenologs, indicating that the presence of two T3SSs in a species did not result from a gene duplication event inside the species but rather is the consequence of two successive horizontal gene transfers (Troisfontaines and Cornelis, 2005).

So far, most described horizontal transfer of T3SS encoding gene clusters occurred among species sharing similar ecological niches (e.g. between plant pathogens or animal pathogens, but not from animal to plant pathogens), again indicating that physical proximity between donor and acceptor bacteria is indispensable for horizontal gene transfer events.

Translocation of effectors - models

The global architecture of the structural components in the bacterial membranes is well conserved among the different families of T3SSs. The basal structure consists of a cylindrical structure spanning the inner and outer membrane, associated with a C-ring like structure (homologous to the flagellum MS ring) and an ATPase. Depending on the families, a hollow stiff needle, a filament or a pilus extends from the basal structure, and consists of 100-150 molecules arranged according to a helical polymerization pattern (Blocker et al., 2008). Its length varies from 40 to $80 \mathrm{~nm}$ in animal pathogens, up to several $\mu \mathrm{m}$ in the plant pathogen Pseudomonas syringae allowing to protrude the thick plant cell wall (Cornelis, 2006). Upon contact with a target cell, a hetero-oligomeric translocation pore is built into the host cell membrane. Generally, three translocators make up the pore (e.g. YopB, YopD and LcrV in Yersinia spp.; IpaB, IpaC and IpaD in Shigella spp.), only the third ( $\mathrm{LcrV}, \mathrm{IpaD}$ ) of which is hydrophilic, serving as a scaffold for the other, hydrophobic, translocators (Cornelis, 2006). In plant pathogens, only one T3SS translocon protein family has been identified so far, HrpF/NopX/PopF, exhibiting only limited homology to the YopB family from animal-pathogenic bacteria (Meyer et al., 2006). However, the HrpF homologs from Xanthomonas oryzae pv. oryzae and Pseudomonas syringae pv. tomato are not essential for bacterial pathogenicity, suggesting that additional proteins are involved (Buttner and Bonas, 2006).

The internal central channel of the whole system is approximately 2-3 nm in diameter, which is too small to allow folded proteins to pass through the tube. Therefore, effector proteins need to be unfolded prior to translocation (see further).

For animal-infecting bacteria, mechanisms of how T3SEs interact with the host cell are largely unknown, unlike for plant pathogens, whose primary role is to suppress the basal defence response. Described mechanisms include suppression of defence signaling, salicylic-acid dependent and cell wall based defences, as well as alteration of ethylene production. However, they may also induce a strong defence response, if the host possesses a specific resistance protein corresponding to a particular avirulence (Avr) protein (McCann and Guttman, 2008).

\section{Substrate recognition - In search of the bar code}

Whether or not T3SEs contain a conserved signal sequence has long been debated and research has predominantly focused on Yop effectors of Yersinia spp. It was first proposed that the secretion signal was an encrypted non-cleaved amino terminal sequence in the protein as these amino termini showed no significant amino acid homology. Relatively radical changes in amino acid sequence did not affect secretion, suggesting that the secretion signal of T3SEs was conformational rather than sequence based (Michiels and Cornelis, 1991). Anderson and Schneewind (1997) postulated that the signal was embodied within the 5' region of the mRNA coding for the substrate and that secretion was coupled to translation. 


\section{Beeckman and Vanrompay}

Table 2: Frequently used nomenclature for the conserved structural proteins of the T3SS across the different families and their homologs in the flagellum. Legend: Chlam.: Chlamydiales; Rhiz.: Rhizobiales; TL: translocon component; IM: inner membrane; IM: outer membrane; CP: cytoplasmic; MA: membrane associated; HCM: host cell membrane. Adapted from Hueck (1998), Meyer et al. (2006), Blocker et al. (2008) and Mueller et al. (2008).

\begin{tabular}{|c|c|c|c|c|c|c|c|c|c|}
\hline Sct & Ysc-Yop & SPI-1 & SPI-2 & Hrc1 & Hrc2 & Chlam. & Rhiz. & Flagella & Subcellular localization \\
\hline SctV & $\begin{array}{l}\text { YscV } \\
\text { LcrD }\end{array}$ & $\begin{array}{l}\text { InvA } \\
\text { MxiA }\end{array}$ & SsaV & $\begin{array}{l}\text { HrcV } \\
\text { Hrpl }\end{array}$ & $\begin{array}{l}\mathrm{HrcV} \\
\mathrm{HrpO}\end{array}$ & $\begin{array}{l}\text { SctV } \\
\text { CdsV } \\
\text { LcrD } \\
\end{array}$ & PcrD & FlhA & IM \\
\hline SctW & $\begin{array}{l}\text { YscW } \\
\text { YopN } \\
\text { LcrE }\end{array}$ & $\begin{array}{l}\text { InvE } \\
\text { MxiC }\end{array}$ & I & HrpJ & I & $\begin{array}{l}\text { SctW } \\
\text { CopN } \\
\text { LcrE }\end{array}$ & I & I & Secreted \\
\hline SctN & YscN & $\begin{array}{l}\text { InvC } \\
\text { Spal }\end{array}$ & SsaN & $\mathrm{HrcN}$ & $\begin{array}{l}\mathrm{HrcN} \\
\mathrm{HrpE}\end{array}$ & $\begin{array}{l}\text { SctN } \\
\text { CdsN }\end{array}$ & $\mathrm{HrcN}$ & Flil & $\mathrm{CP}, \mathrm{MA}$ \\
\hline SctO & $\mathrm{YscO}$ & $\begin{array}{l}\text { Invl } \\
\text { SpaM }\end{array}$ & SsaO & $\mathrm{HrpO}$ & 1 & $\begin{array}{l}\text { SctO } \\
\text { CdsO }\end{array}$ & ORF7 & I & $?$ \\
\hline SctP & YscP & $\begin{array}{l}\text { InvJ } \\
\text { SpaN }\end{array}$ & SsaP & HrpP & I & $\begin{array}{l}\text { SctP } \\
\text { CdsP }\end{array}$ & I & I & Secreted \\
\hline SctQ & YscQ & $\begin{array}{l}\text { InvK } \\
\text { SpaO }\end{array}$ & SsaQ & $\begin{array}{l}\mathrm{HrcQ} \\
\mathrm{A} \& \mathrm{~B}\end{array}$ & $\begin{array}{l}\text { HrcQ } \\
\text { HrpQ }\end{array}$ & $\begin{array}{l}\text { SctQ } \\
\text { CdsQ }\end{array}$ & $\mathrm{HrcQ}$ & $\begin{array}{l}\text { FliN } \\
\text { FliM } \\
\text { FliY }\end{array}$ & IM \\
\hline SctR & YscR & $\begin{array}{l}\text { InvL } \\
\text { SpaP }\end{array}$ & SsaR & $\begin{array}{l}\text { HrcR } \\
\text { HrpW }\end{array}$ & $\begin{array}{l}\text { HrcR } \\
\text { HrpT }\end{array}$ & $\begin{array}{l}\text { SctR } \\
\text { CdsR }\end{array}$ & HrcR & FliP & $\mathrm{IM}$ \\
\hline SctS & YscS & $\mathrm{SpaQ}$ & SsaS & $\begin{array}{l}\mathrm{HrcS} \\
\mathrm{HrpO}\end{array}$ & $\begin{array}{l}\text { HrcS } \\
\text { HrpU }\end{array}$ & $\begin{array}{l}\text { SctS } \\
\text { CdsS }\end{array}$ & HrcS & FliQ & $\mathrm{IM}$ \\
\hline SctT & YscT & $\begin{array}{l}\text { InvN } \\
\text { SpaR } \\
\end{array}$ & SsaT & $\begin{array}{l}\text { HrcT } \\
\text { HrpX }\end{array}$ & $\begin{array}{l}\mathrm{HrcT} \\
\mathrm{HrpC} \\
\end{array}$ & $\begin{array}{l}\text { SctT } \\
\text { CdsT }\end{array}$ & HrcT & FliR & $\mathrm{IM}$ \\
\hline SctU & YscU & SpaS & SsaU & $\begin{array}{l}\mathrm{HrcU} \\
\mathrm{HrpY}\end{array}$ & $\begin{array}{l}\mathrm{HrcU} \\
\mathrm{HrpN}\end{array}$ & $\begin{array}{l}\text { SctU } \\
\text { CdsU }\end{array}$ & $\mathrm{HrcU}$ & FlhB & IM \\
\hline SctC & YscC & $\begin{array}{l}\text { InvG } \\
\text { MxiD }\end{array}$ & $\begin{array}{l}\text { SsaC } \\
\text { SpiA }\end{array}$ & $\begin{array}{l}\mathrm{HrcC} \\
\mathrm{HrpH}\end{array}$ & $\begin{array}{l}\text { HrcC } \\
\mathrm{HrpA}\end{array}$ & $\begin{array}{l}\text { SctC } \\
\text { CdsC }\end{array}$ & NolW & I & OM \\
\hline SctD & YscD & 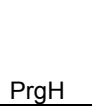 & $\begin{array}{l}\text { SsaD } \\
\text { SpiB }\end{array}$ & $\mathrm{HrpQ}$ & $\begin{array}{l}\text { HrpW } \\
\text { HrpD5 }\end{array}$ & $\begin{array}{l}\text { SctD } \\
\text { CdsD }\end{array}$ & I & FliG & IM \\
\hline SctF & YscF & $\begin{array}{l}\text { MxiH } \\
\text { Prgl } \\
\end{array}$ & SsaG & I & 1 & $\begin{array}{l}\text { SctF } \\
\text { CdsF }\end{array}$ & I & 1 & Needle \\
\hline Sctl & $\begin{array}{l}\text { Yscl } \\
\text { LcrO }\end{array}$ & PrgJ & I & HrpB & I & I & I & I & $\mathrm{CP} ?$ \\
\hline SctJ & $\begin{array}{l}\text { YscJ } \\
\text { YlpB }\end{array}$ & $\begin{array}{l}\text { MxiJ } \\
\text { PrgK }\end{array}$ & SsaJ & HrcJ & $\begin{array}{l}\text { HrcJ } \\
\text { Hrpl }\end{array}$ & $\begin{array}{l}\text { SctJ } \\
\text { CdsJ }\end{array}$ & NolT & FliF & Link between IM and OM \\
\hline SctK & YscK & 1 & I & HrpD & I & I & I & I & $\mathrm{CP} ?$ \\
\hline SctL & YscL & I & SsaK & HrpE & $\mathrm{HrcL}$ & $\begin{array}{l}\text { SctL } \\
\text { CdsL }\end{array}$ & NolV & FliH & $\mathrm{CP}$ \\
\hline TL & YopB & $\begin{array}{l}\text { SipB } \\
\text { IpaB }\end{array}$ & SseC & HrpK & $\begin{array}{l}\text { PopF } \\
\text { HrpF } \\
\text { NopX }\end{array}$ & CopB1/2 & 1 & 1 & $\mathrm{HCM}$ \\
\hline TL & YopD & $\begin{array}{l}\text { SipC } \\
\text { IpaC }\end{array}$ & SseD & I & I & CopD1/2 & 1 & l & $\mathrm{HCM}$ \\
\hline TL & LcrV & $\begin{array}{l}\text { SipD } \\
\text { IpaD }\end{array}$ & SseB & I & I & LcrV & I & I & $\mathrm{HCM}$ \\
\hline
\end{tabular}

Further research indicated that a physical property, namely amphipathicity, of the amino terminus is critical for secretion, although at least some secondary signal might reside in the mRNA (Lloyd et al., 2001). More recent research indicates the presence of a chaperonebinding domain (CBD) located within the first 100 amino acids of the effector protein, downstream from a short, uncleaved, amino terminal export signal (Birtalan et al., 2002).

A more detailed discussion on this topic can be found in Sorg and Cornelis (2009). In Chlamydiaceae, the bilobed hydrophobic domain of the inclusion membrane proteins (Incs) was proven indicative for secretion by a T3SS (Subtil et al., 2001). Research by the same group indicated that, for Chlamydiaceae as well, a signal must be present within the 14 amino terminal amino acids of effector proteins, although no conserved sequence pattern could be detected (Subtil et al., 2005). Based on these observations a prediction tool for T3SEs was developed: EffectorT3, which is available online at www.chlamydiaeDB.org. Tests across different taxa indicate that a common mechanism is not restricted to a 
certain phylum, and that the ability to be transported by the T3SS seems to have been re-invented by different families of effectors several times (Arnold et al., 2009).

\section{Specific T3SS chaperones}

Generally spoken, chaperones assist in folding or unfolding and assembly or disassembly of macromolecular structures, such as proteins or protein complexes. Based on structural and functional analyses, at least five classes of specific T3SS chaperones can be distinguished. Chaperones of Class I assist the effector proteins, while Class II chaperones interact with the translocator proteins. Class III groups the chaperones of the related bacterial flagellar apparatus. Class IV is represented by only one member, CesA (chaperone for $E$. coli secretion A), accompanying the EspA filament protein of enteropathogenic E. coli (Yip et al., 2005). Yersinia YscE and its Pseudomonas homolog PscE, with their co-chaperones YscG and PscG, are classified as Class V (Wilharm et al., 2007). Class I and Class II chaperones are well characterized and will be discussed in further detail.

\section{Class I chaperones}

As mentioned above, Class I chaperones specifically interact with the T3SEs. A distinction is made whether only a single substrate is bound (Class IA, which is the case for the majority of them), or whether multiple substrate proteins can be served (Class IB, the so-called 'promiscuous chaperones'). Common features include their small size, acidic pl, their dimeric nature and being encoded adjacent to their corresponding cognate effector gene (Pallen et al., 2005). Although exhibiting a very low sequence homology (maximum 20\% when aligning two different chaperone sequences), they do share a conserved fold. Moreover, T3SEs wrap their CBD around chaperone homodimers to bind hydrophobic regions on the surface of the chaperones. The common fold may therefore reflect a shared effector recognition pattern (Wilharm et al., 2007). Functions attributed to the chaperones include acting as a 3D export signal, establishing a temporal export hierarchy and storage of the effector proteins in an exportcompetent state prior to export. In addition, their presence could direct the effector protein to the ATPase, which unfolds exported proteins in an ATP-dependent manner and subsequently detaches the chaperone from its substrate, a function similar to that done by the bacterial $\mathrm{AAA}^{+}$ATPase disassembly machineries (Akeda and Galan, 2005; Sorg and Cornelis, 2009).

\section{Class II chaperones}

Class II chaperones protect bacteria from the toxic properties exerted by the hydrophobic translocator proteins (Menard et al., 1994; Wattiau et al., 1994; Neyt and Cornelis, 1999). Examples are IpgC of Shigella flexneri, LcrH (SycD) of Yersinia spp., and Scc2/3 of Chlamydiaceae. All Class II chaperones share the same structure of three tandem tetratricopeptide repeats (TPRs), consisting of 34 amino acids per repeat and involved in protein-protein interactions (Pallen et al., 2003b). Similar repeats can be found in host cell chaperones Hsp70 and Hsp90. Darwin and Miller showed that unbound SicA of S. typhimurium interacts with the transcriptional regulator InvF, to activate transcription from the effector gene promoters (Darwin and Miller, 2000). A similar transcriptional regulation has been described for IpgC in conjunction with MxiE (Mavris et al., 2002), while LCrH is presumed to be involved in mRNA degradation (Anderson et al., 2002). The higher concentration of free chaperones upon assembly of the translocon in the host cell membrane could then inform the bacterium that the pore is made and the T3SS is fully functional (Page and Parsot, 2002). Fascinatingly, the plant-associated Hrc1 and Hrc2 T3SSs do not seem to employ TPR chaperones (Pallen et al., 2005).

How these translocator chaperones exactly bind to their substrates is still a matter of debate. Is the CBD a unique region or not? Do they form a complex with both translocators or are both substrates bound independently in the cytoplasm? An overview on these topics and the stability of translocator-chaperone complexes can be found in Sorg and Cornelis (2009).

\section{T3SS in Chlamydiales}

\section{History and first evidence of a chlamydial T3SS}

Long before the first visualization of a T3SS in Salmonella (Kubori et al., 1998), Matsumoto and coworkers already described the presence of rosette-like structures and projections on the surface of both elementary bodies (EBs) and reticulate bodies (RBs) of different chlamydial species (Matsumoto, 1973; 1982b; Matsumoto et al., 1976). These hexagonally arranged patches, delineating a zone of close contact between the $\mathrm{RB}$ and inclusion membrane were long thought to facilitate the uptake of nutrients from the host cell cytoplasm, an idea designated as the "soup-through-astraw" hypothesis (Stephens, 1992). The first indication for the existence of a chlamydial T3SS came from Hsia et al. (1997) who identified a locus of seven, nonoverlapping open reading frames in Cp. caviae GPIC, the first four of which encode proteins with significant homology to T3SS proteins in other species. Shortly thereafter the same group postulated that the envelope spanning components of the chlamydial surface projections represent the chlamydial T3SS. The observation that this type of 'contact dependent secretion' is present in contact zones, protruding both IM and $\mathrm{OM}$ as well as the host cell membrane is consistent with a channel mediating the translocation of proteins from the bacterial cytoplasm into the host cell cytosol (Bavoil and Hsia, 1998). Subsequent genomic analysis revealed the presence of a complete set of T3S encoding genes in all Chlamydiaceae species sequenced so far (Stephens et al., 1998; Read et al., 2000; Shirai et al., 2000; Kalman et al., 1999; Azuma et al., 2006; Read et al., 2003; Thomson et al., 2005) as is the case for the environmental chlamydiae $P$. amoebophila UWE25 (Horn et al., 2004) and Simkania negevensis (Peters et al., 2007, Meyers et al., unpublished results).

\section{Genetic organization}

Chlamydiales are the only non-Proteobacteria that harbor a T3SS (Troisfontaines and Cornelis, 2005). In most Proteobacteria, genes encoding the structural components of the T3SS are clustered within a single chromosomal PAI or on a virulence-associated plasmid, 
with sizes up to $200 \mathrm{kbp}$, flanked by vestiges of recent integration events, e.g. direct repeats or insertion sequences (IS) (Winstanley and Hart, 2001) and within the different T3SS families, gene order within the loci is well conserved (see above). By contrast, genes coding for the chlamydial T3SS are located in at least four clusters dispersed throughout the genome, predominantly coding for structural components, specific chaperones for effector proteins, and two translocator systems to transport secreted proteins across the host cell membrane, at least in Chlamydiaceae. The presence and location of effector encoding genes, but not structural genes differs between the species (Figure 2).

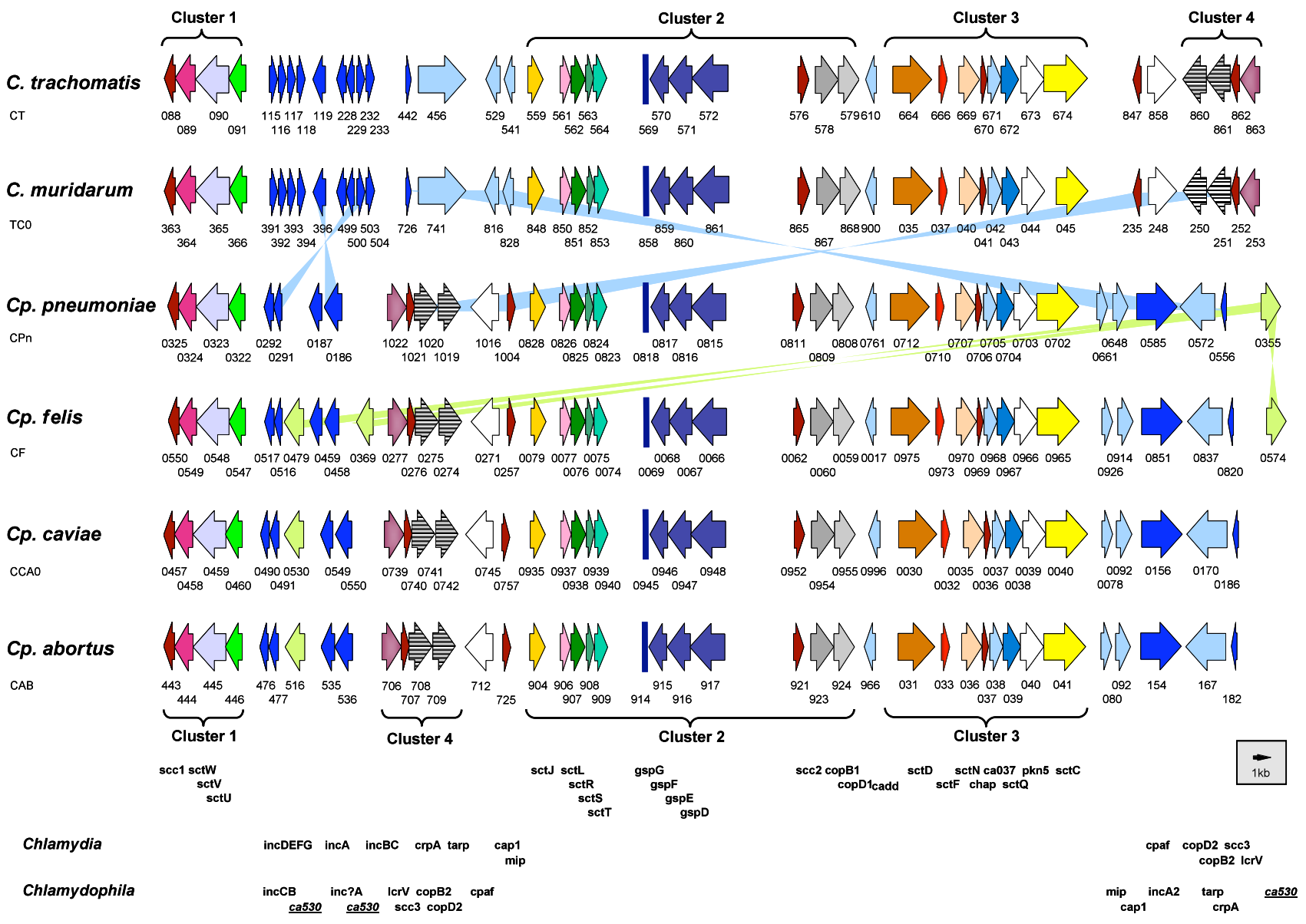

Figure 2: Comparison of the genetic organization of the T3SS genes of six different species of the Chlamydiaceae. Below each species, genes are numbered with the locus tag of the GenBank genome files (NC 000117, NC 002620, NC 000922, NC 007899, NC 003361 and NC 004552, respectively). Genetic organization in $\mathrm{Cp}$. psittaci is presumed to be highly similar to that of $\mathrm{Cp}$. abortus as $\mathrm{Cp}$. $\bar{p}$ sittaci strains resemble what might have been recent ancestors of Cp. abortus (Van Loock et al., 2003). Positions of corresponding homologs are indicated by color codes. Note that structural proteins [unified nomenclature after Hueck (1998)] appear in the same order in both genera, while (putative) effector proteins do not. The distance within the clusters is in scale, the distance between the clusters is not.

The first structural cluster of T3SS genes (sctU, sctV, sctW and scc1) was discovered in Cp. caviae (Hsia et al., 1997) (

Figure 2, cluster 1). The incDEFG effector cluster (Scidmore-Carlson et al., 1999) is presumably specific for Chlamydia since psi-blast searches (Hsia et al., 1997 ) did only reveal homologs in C. muridarum and not in Chlamydophilae. The same is true for the CT228-229 cluster in C.trachomatis and its homologs in C. muridarum. IncA is immediately adjacent to this cluster in Chlamydia. The incBC cluster which is found $125 \mathrm{~kb}$ downstream of incA in C. trachomatis, is flipped to incCB and lies in front of it in Chlamydophila. The second structural cluster contains genes coding for SctJLRST as well as Scc2 and YopB/YopD homologs (translocator components CopB/CopD). A third structural cluster contains $\operatorname{sct} D, \operatorname{sct} N$, sctQ and $\operatorname{sct} C$ as well as the Type III secretion (T3S) effector genes ca037 (sctP) (Subtil et al., 2005), pkn5 and a gene coding for a putative SctN chaperone (chap). The tarp gene is found before the second and third cluster in Chlamydia, together with effector encoding genes $\operatorname{crp} A$, cap1 and mip. In Chlamydophila, the same genes are present on the complementary strand downstream of the third cluster. For $s c c 3, c o p B 2, c o p D 2$ and $I c r V$ it is vice versa, as is for CT847 and its homologs.

In $P$. amoebophila UWE25 genes for only one translocon component (CopB, PC1385) and five putative translocon chaperones (PC1384, PC1386, PC0787, PC1525 and $\mathrm{PC} 1110)$ are present, while no translocon components or associated chaperones are encoded within the Simkania negevensis genome (Peters et al., 2007) and 
most effector encoding genes identified so far in Chlamydiaceae are absent from the environmental chlamydiae.

Genes coding for Type III secretion are usually low in GC content (40-45\%) when compared to the rest of the genome (Hueck, 1998; Subtil et al., 2000). In Chlamydiaceae however, the GC content of the chlamydial T3S apparatus equals the GC content of the rest of the genome (approximately 40\%) and no remnants of recent gene integration seem to flank the different T3SS gene clusters (Subtil et al., 2000).

Both the genetic organization in PAls and the low GC content suggest that T3S genes originated in a chlamydial ancestor and were subsequently transferred to the Proteobacteria by means of horizontal gene transfer. This is corroborated by the fact that when constructing phylogenetic trees for some T3SS components, the chlamydial homologs are often placed at the bottom of the tree (Kim, 2001; Gophna et al., 2003). Moreover, the presence of T3S genes in environmental chlamydiae suggests that T3S was likely to be present in this lineage more than 700 million years ago, around the time that symbiotic and pathogenic chlamydiae diverged (Horn et al., 2004). The apparent absence of a T3SS in $\varepsilon$-Proteobacteria is probably due to subsequent gene loss.

The presence of four gsp genes in cluster 2 is not remarkable since assembly of the T3SS is probably dependent on the Sec-pathway (see above).

\section{Composition of the chlamydial T3SS}

In this section we will further focus on the composition and regulation of the chlamydial T3SS. As its closest phylogenetic relative is that of $Y$. pestis (Peters et al., 2007), many assumptions on the chlamydial T3SS are based on information on assembly and regulation of the Ysc-Yop T3SS in Yersinia.

Towards a unified nomenclature

In the past years, genes encoding structural components and chaperones of the chlamydial T3SS have been designated Ysc (Yersinia secretion), Lcr (low calcium response) or Syc (specific Yersinia chaperone) after the Yersinia T3SS. With T3SSs found in such a wide range of Proteobacteria, nomenclature of T3SS related genes and proteins became difficult to follow, as each protein is known by many different names according to species, first discovered function, etc. In a 'tour de force' to facilitate interpretation of T3S related research, a unified nomenclature was suggested by Hueck, who used the abbreviation Sct (secretion and cellular translocation), followed by a specific suffix, e.g. SctR, for the conserved structural core of the syringe, giving only chaperones and effectors in its load species specific names (Hueck, 1998). Another nomenclature system, this time specific for chlamydiae was proposed by Fields et al., who chose to use the original cds (contact dependent secretion) designation of Hsia et al. (1997) with the letter suffixes of the unified system (Fields et al., 2003), except for CopN (SctW), where the original designation of Hsia was kept (Hsia et al., 1997).

As chlamydiae have recently been suggested to possess the most ancient non-flagellar T3SS (Pallen et al., 2005; Troisfontaines and Cornelis, 2005), the unified Sct nomenclature as proposed by Hueck for the conserved structural proteins of the T3SS is used throughout this review. Chaperones and effectors were given their species specific names.

\section{Model of the chlamydial T3SS}

Depending on the species, 20 to 30 genes have been predicted or proven to encode T3SS structural proteins and chaperones. Homologous to the related flagellar system, components are classified into 1) the exporter, enveloping the basal body, 2) the basal body itself in the inner membrane, 3) the secreton piercing the outer membrane 4) the needle and 5) the translocon, assembling in the eukaryotic membrane at the top of the needle. One of the key players is the cytoplasmic inner membrane associated ATPase SctN, to energize the apparatus. Structural components assemble to form a molecular syringe for direct translocation of effector proteins into the eukaryotic host cell, and although still uncovered, the Sec-pathway is thought to be involved. Additionally, the specific chlamydia chaperones Scc1 and Scc2/3 (homologs of SycE and SycD/LcrH, respectively) assist translocation, while the regulatory protein SctW (or chlamydial outer protein CopN) is predicted to function similar to a cork on a flask. Chlamydiaceae actively modify inclusion membranes with a set of T3S effector proteins, known as inclusion membrane proteins or Incs (Subtil et al., 2001; Fields and Hackstadt, 2002; Rockey et al., 2002).

The degree of homology between T3S proteins from different organisms varies: from highly conserved (especially in the exporter and the basal body) to quite divergent (chaperones, translocon components) and even inapparent or absent (effector proteins). This decrease in homology corresponds to the organization of the T3SS, the molecular equivalent of a syringe, from the inside to the outside, the outside being subjected to a larger evolutionary pressure. At least 11 proteins have homologs in all currently described T3SSs: SctC, D, J, L, N, Q, R, S, T, U, V (Cornelis and Van Gijsegem, 2000). What follows is a general description of how the chlamydial T3SS might be composed (Figure 3), from the inside of the syringe to the top of its needle. The closer we get to the top of the needle, the more difficult it becomes to assign general functions to the components.

\section{Exporter}

The exporter consists of several proteins located in the inner membrane at its cytoplasmic face, surrounding the basal body and mediating active transport to the periplasmic space. It is composed of two families of proteins, on the one hand SctR, $S$ and $T$ and on the other hand SctU, $V$ and $N$, which uses energy from ATP to export proteins across the IM (Aizawa, 2001).

SctR. The SctR protein is homologous to the Yersinia secretion protein $\mathrm{R}$ (YscR). In Yersinia this component may have a role in the negative pathway regulation of the calcium controlled Yop expression. SctR is an integral inner membrane protein paralogous to the basal body associated FliP of the flagellar apparatus (Aizawa, 2001). Models show a weakly conserved 70 amino acid hydrophilic domain and four predicted transmembrane helices with periplasmic amino and carboxy termini (Hueck, 1998) or three transmembrane domains with a cytoplasmic amino terminus and a periplasmic carboxy 

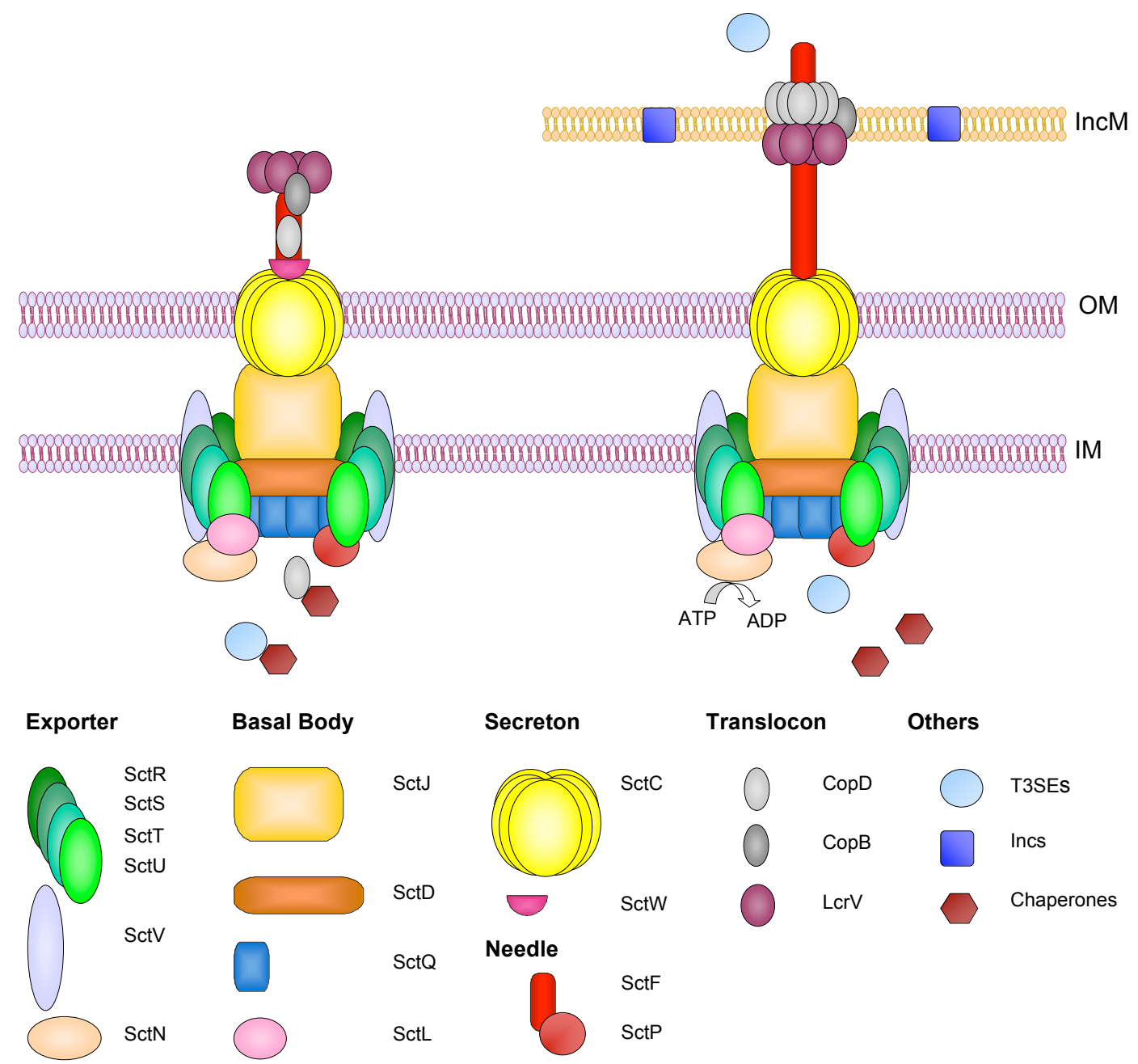

Figure 3: Type III secretion system in Chlamydiaceae. On the left side, an inactive T3SS is shown, while the right side depicts the T3SS after activation. Prior to contact with the host cell, only LrcV is supposed to be present at the tip of the needle and secretion is regulated by SctW. Translocon component CopD is bound to its chaperone, as is the case for effector proteins. Upon host cell recognition, Cops are built into the eukaryotic membrane on top of an LcrV scaffold, thus allowing translocation of unfolded, unchaperoned effectors to the host cell cytoplasm. Legend: IM, bacterial inner membrane; OM, bacterial outer membrane; IncM, inclusion membrane. Refer to the text for details.

terminus (Ghosh, 2004). In Cp. psittaci, SctR is predicted to have five transmembrane segments (Beeckman et al., 2008).

SctS. SctS has two predicted transmembrane domains (Hueck, 1998) with probably cytoplasmic termini. It shows homology to FliQ of the flagellar system (Aizawa, 2001).

SctT. Similar to SctS and SctR and paralogous to flagellar FliR (Aizawa, 2001), SctT is an integral membrane protein, this time with six predicted transmembrane domains and the amino and carboxy termini presumably in the periplasm (Hueck, 1998).

SctU. SctU is homologous to YscU, an inner membrane protein with four transmembrane segments anchoring a large cytoplasmic carboxy terminal domain to the inner membrane (Allaoui et al., 1994). Its paralog in flagella is FlhB. Cleavage of Yersinia YscU is needed to acquire a conformation allowing recognition and subsequent membrane insertion of the translocon components (Sorg et al., 2007). In Chlamydiaceae, SctU was first discovered in Cp. caviae and was originally called Cds1
(Hsia et al., 1997). In C. trachomatis, RT-PCR analysis showed sctU expression from $12 \mathrm{~h}$ onwards (Fields et al., 2003) while sctU expression was not detected in Cp. pneumoniae (Slepenkin et al., 2003), suggesting variable importance of SctU in chlamydiae.

SctV. SctV is predicted to form a central proteinconducting channel across the inner membrane, based on its homology to Yersinia LcrD/YscV. These proteins are predicted to have at least six amino terminal transmembrane segments that anchor a large cytoplasmic carboxy terminal domain into the inner membrane (Plano et al., 1991). In Chlamydiaceae, SctV was originally detected in Cp. caviae and called Cds2 (Hsia et al., 1997).

SctN. This protein belongs to the family of cytoplasmic ATPases and demonstrates extensive homology with the ATP synthase F1 beta subunit (Woestyn et al., 1994). Following oligomerization into a dodecamer (Pozidis et al., 2003; Muller et al., 2006), it uses ATP to energize the T3SS or at least a part of it. Its subcellular location is cytoplasmic, but it is connected to the inner membrane, 
possibly through SctV, although binding is probably not required for proper function. Three highly conserved regions are found: ATP/GTP binding domains $A$ and $B$ also called walker boxes $A$ and $B$ (Walker et al., 1982) and a $\mathrm{Mg}^{2+}$ binding motif (Yoshida et al., 1982). Cp. pneumoniae SctN interacts with the basal body components, SctD, $Q$ and $L$ as well as the regulator protein SctW (Stone et al., 2008) and is also believed to play a role in the delivery of effector proteins through ATP-dependent unfolding of proteins and releasing the chaperone from its substrate prior to translocation (Akeda and Galan, 2005; Sorg and Cornelis, 2009).

\section{Basal body}

The basal body of the T3SS is located in the bacterial cytoplasm and is necessary for correct anchoring of the needle complex. The sct $Q, R, S, T, U, V$ and $J$ genes all show significant homology to the genes of the flagellar system, indicating that their corresponding proteins are localized in or at least associated with the inner membrane. Both sctD and sctL show weaker homologies to their flagellar counterparts.

SctD. The 3' region of the C. trachomatis CT664 gene has homology to $y s c D$ but is not consistently reported as a possible component of the chlamydial T3SS (Kim, 2001). SctD resembles the Salmonella PrgH required for anchoring of the Salmonella needle complex (Kubori et al., 1998). Two forkhead-associated (FHA) putative nuclear signaling domains of approximately 55 to 75 amino acids are present in the amino terminal region, and pull down assays suggest that SctD interacts with Cp. pneumoniae SctL and SctQ, probably through its carboxy terminus (Johnson et al., 2008).

SctJ. Most members of the SctJ family are lipoproteins, as they carry a characteristic lipid attachment site motif LxGC at the amino terminus as well as a hydrophobic stretch of 20 to 30 amino acids at the carboxy terminal end. They represent the morphogenic equivalent of the flagellar rotor FliF (MS ring) and probably bridge the inner and outer membranes (Allaoui et al., 1992; Hueck, 1998).

SctQ. Proteins belonging to the SctQ family are peripheral cytoplasmic proteins with a strongly conserved carboxy terminus and a variable amino terminus. Homology to flagellar proteins FliM and FliN has been reported (Aizawa, 2001; Ghosh, 2004) and functionally they are thought to link the conserved structural components to variable species-specific components as recombinant Yersinia YscQ provides a link between YscK and YscL (Jackson and Plano, 2000). In $\mathrm{Cp}$. pneumoniae, cytoplasmic SctQ may play a role in shuttling chaperone/effector complexes to the ATPase SctN (Stone et al., 2008), apart from its interaction with SctW (R. Toor et al., unpublished data). Furthermore, SctQ contains a "surface presentation of antigens" (SpoA) domain and is thought to be incorporated in the chlamydial T3SS as tetramer (Johnson et al., 2008).

SctL. Members of the YscL family are mainly hydrophilic. Although little is known about their function, they probably act in a similar way to SctQ, as yeast three-hybrid studies showed that recombinant YscL linked $Y s c N$ and $Y s c Q$, suggesting that a complex composed of YscN, YscQ, YscK and YscL is involved in the assembly and/or function of the $Y$. pestis Type III secretion apparatus (Jackson and Plano, 2000). In
Cp. pneumoniae, SctL is shown to form dimers (Stone et al., 2008).

\section{Secreton}

The secreton is defined as the collection of outer membrane proteins involved in the transport of effectors and translocon components across the outer membrane. SctC. SctC is clearly an outer membrane protein (Plano and Straley, 1995), forming a channel absolutely necessary for T3S. SctC has no paralogs in the flagellar system but belongs to the large GspD family of bacterial and phage proteins involved in transport of large molecules across the outer membrane (see above). Secretins form stable multimeric ring-like structures (Genin and Boucher, 1994) of around $600 \mathrm{kDa}$ with an external and internal diameter of 200 and $50 \mathrm{~nm}$, respectively. Interestingly, their ultrastructure shows similarity to the rosette-like structures described by Matsumoto (Matsumoto, 1973; 1982b; Matsumoto et al., 1976).

SctW. This gene was first discovered in $Y$. enterolitica and originally named LcrE, Ysc4b or YopN (Viitanen et al., 1990). The chlamydial homolog SctW (CopN) was discovered in Cp. caviae (Hsia et al., 1997) where it might control the polarized contact-dependent secretion of other Cops, and thus seems be involved in a mechanism for regulating the activity of the T3SS (Cheng et al., 2001). Fields and Hackstadt (2000) showed C. trachomatis SctW to be associated with the inclusion membrane and to be T3SS secreted by a heterologous Yersinia system. Homologs of this protein return in all T3SSs, are mainly surface associated (Forsberg et al., 1991) and at some stages associated with the basal body or the secreton. Regarding its function, there is controversy whether SctW should be regarded as an outer membrane protein of the secreton, or rather be classified as an effector. Expression of SctW might provoke detachment of C. trachomatis RBs from the inclusion membrane, shutting off the T3SS as a consequence (see further).

\section{Needle}

The needle is the hollow conduit through which the T3SS proteins travel to cross the membranes and the peptidoglycan layer, which is not present in chlamydiae (Hatch, 1996; Moulder, 1993).

SctF. In Yersinia, the needle consists of approximately 150 YscF subunits, on top of which up to five LcrV molecules are attached (Broz et al., 2007). Recently, the C. trachomatis needle subunit SctF was identified as CT666 using a bioinformatics approach. The protein is concentrated in the outer membrane of EBs and is surface exposed as a component of an extracellular needle-like projection. During infection, SctF is localized in the inclusion membrane adjacent to membraneassociated RBs (Betts et al., 2008).

SctP. A gene encoding an YscP homolog, the ruler protein acting as a molecular ruler controlling the length of the needle (Journet et al., 2003), has not yet been identified in chlamydiae. However, based on sequence homology and its location in the genome, Cpn0705 of Cp. pneumoniae could be a ruler protein, but no further studies have been completed with this protein (Stone et al., 2008). Its homolog in Cp. caviae CCA00037 was previously shown to be secreted by Shigella flexneri, as 
well as the homologous protein from C. trachomatis, CT671 (Subtil et al., 2005).

\section{Translocon}

Upon contact with a target cell, a hetero-oligomeric translocation pore is built into the eukaryotic host cell membrane, consisting of T3SS released proteins assisting translocation into the host cell. In Yersinia, the translocon pore consists of YopB and YopD, on top of an assembly platform of three to five LcrV molecules. Among species, translocator sequences are not conserved, but there are structural similarities in transmembrane segments and coiled-coil regions [reviewed in Mueller et al. (2008)]. In C. trachomatis and Cp. pneumoniae, proteins without signal sequence and with size and hydrophobicity profiles reminiscent to the ones of YopB and YopD were identified as the chlamydial translocators (Subtil et al., 2000). Remarkably, in each species two homologs were found: CT579/Cpn0808 or copD and CT860/Cpn1019 or copD2 as homolog for yopD and CT578/Cpn0809 or copB and $C T 861 / C p n 1020$ or $c o p B 2$ in close proximity to the $s y c D$ chaperone homologs CT576/Cpn0811 (scc2 or IcrH1) and CT862/Cpn1021 (scc3 or IcrH2), respectively.

CopB. CopB1 was the first chlamydial homolog of YopB and it functions as a putative translocator component of the chlamydial T3SS, consistent with its presence in the C. trachomatis inclusion membrane. On the contrary, CopB2 was demonstrated in the host cell cytosol (Fields et al., 2005).

CopD. CopD1 and CopD2 are the chlamydial YopD homologs, with CopD1 being translocated through the heterologous SPI-2 T3SS of S. enterica sv. typhimurium (Ho and Starnbach, 2005).

LcrV. The needle culminates in a tip complex consisting of multiple copies of a protein of the LcrV family, also known as adaptor proteins (Blocker et al., 2008). In addition to its essential role in the insertion of the translocators into the host cell membrane, the Yersinia LcrV pentamer on top of the T3SS needle is involved in host cell sensing and causes immunosuppression by triggering IL-10 release by macrophages [reviewed in Hamad and Nilles (2007)]. Until now, no LcrV homolog had been identified in chlamydiae (Stone et al., 2008). However, all currently sequenced Chlamydiaceae contain at least one LcrV encoding gene in their genome, adjacent to the $s c c 3 / \operatorname{cop} B 2 / D 2$ gene cluster (cluster 4 in

Figure 2, author contribution). Whether the corresponding protein is functional is elusive and requires further attention.

\section{Chaperones}

Type III secretion chaperones are specific, associating with one or multiple secretion substrates, typically encoded on an adjacent gene. Their function includes stabilizing their target, maintaining a secretion competent state or serving as a secretion pilot. In Yersinia, they are also involved in establishing a secretion hierarchy and participate in feedback regulatory cascades [overview in Fields and Hackstadt (2006)]. The chlamydial genomes contain at least nine predicted T3S chaperones, at least seven of which contain predicted amphipathic helices. These will now be discussed in further detail.
Scc1. Scc1 is the Specific chlamydia chaperone 1 discovered by Hsia et al. (1997), CT088 in C. trachomatis. Scc1 shares limited sequence similarity to SycE of Yersinia spp., a rather small protein of about $15 \mathrm{kDa}$ carrying a carboxy terminal amphipathic alpha helix. SycE family members are acidic (pl 4,4-5,2) and bind their secreted or translocated partner, which is YopE in the case of SycE (Cornelis, 2000). Moreover Scc1 contains a CesT domain, homologous to the CesT chaperone of the E. coli translocated Tir T3SE protein (Delahay et al., 2002).

CT043 and CT663. As for Scc1, both predicted chaperones contain a CesT domain, but their respective chlamydial substrates have not yet been uncovered.

Scc2/3. Scc2 and Scc3 are homologous to the $\mathrm{LrcH}$ chaperone of the Yersinia translocators, chaperoning CopB1/D1 and CopB2/D2, respectively, in chlamydial T3SSs. As with the other members of the LcrH/SycD family, both Sccs possess three tandem TPRs implicated in protein-protein interactions (Pallen et al., 2003b). In addition, both chaperones associate with YopD in a heterologous Yersinia T3SS and coprecipitate with CopB from C. trachomatis extracts (Fields et al., 2005). Surprisingly, Cp. pneumoniae Scc3, adjacent to CopB2 and CopD2, was found to interact with SctW in a two-hybrid system, suggesting to function as a chaperone for SctW as well (Slepenkin et al., 2005).

CT274. With its typical TPR domain, CT274 and its chlamydial homologs are classified in the group of Class II chaperones, and might therefore be involved in transcriptional regulation of T3S gene expression (see above).

CT665 and CT667. These two recently discovered chaperones are involved in regulation of SctF in C. trachomatis. Originally named CdsE (SctE) and CdsG (SctG), both proteins interact with each other and a SctF-CdsG interaction was only detectable in the presence of CdsE (Betts et al., 2008).

CT670/SctO. Proteins of this family have various sizes and exhibit little sequence similarity. In Yersinia, YscO is a mobile protein required for high-level expression and secretion of LcrV and Yops (Payne and Straley, 1998). Its counterpart in the flagellar system is FliJ, a cytoplasmic protein occupying a chaperone function (Payne and Straley, 1998; Minamino et al., 2000). This is in accordance with the presumed chaperone function of the homologous Cp. pneumoniae Cpn0706 protein (Stone et al., 2008), the encoding gene of which is localized at the predicted location of the sctO gene, in addition to its predicted coiled-coil conformation (unpublished result).

\section{Effector proteins - chlamydial T3SS substrates}

Type III secretion effector proteins are highly divergent, both in sequence and function between T3SS possessing organisms. For instance, Yersinia Yops mainly target the intracellular host cell signaling pathway to benefit their survival outside the cell and escape the innate immunity. On the other hand, Salmonella Sips (SPI-1 T3SEs) induce cell invasion, while Sses from the SPI-2 T3SS aid in proliferation inside macrophages (Hueck, 1998). Unlike in other pathogens with a T3SS, chlamydial effectors are scattered throughout the genome and in the past years, several efforts have been made to identify chlamydial T3SEs (Subtil et al., 2001; 
Fields et al., 2003; Slepenkin et al., 2003; Lugert et al., 2004; Clifton et al., 2005; Subtil et al., 2005; Jamison and Hackstadt, 2008; Kleba and Stephens, 2008), with the family of inclusion membrane proteins (Incs) being the best one characterized so far. Although the Incs exhibit a very low sequence similarity, a characteristic bilobed hydrophobic region of at least 50 amino acids is present in each of them. Biological functions for the Incs have been proposed in the past years. These will briefly be discussed hereafter, but for a more detailed description we refer to an excellent review by Kostryukova et al. (2008). IncA is a serine/threonine phosphoprotein, exposed on the cytoplasmic side of the developing inclusion, where it is phosphorylated by host cell kinases, both during chlamydial infection and endogenous expression of IncA in eukaryotic cells (Rockey et al., 1997). This protein has been extensively studied and is believed to be functionally involved in the homotypic fusion of $C$. trachomatis inclusions (Hackstadt et al., 1999). Decreasing the temperature to $32{ }^{\circ} \mathrm{C}$ is correlated with an impaired export of IncA to the inclusion membrane and delays the formation of a single inclusion (Fields et al., 2002). The biochemical properties of $C$. trachomatis and $C p$. caviae IncA are conserved as both orthologs carry a eukaryotic SNARE domain (responsible for fusion of membrane structures in eukaryotes) and self-associate to form a tetrameric structure similar to the SNARE complex, possibly interacting with eukaryotic SNARES to hijack part of the cellular traffic (Delevoye et al., 2004). The adjacent Cpn0187 is also predicted to be an Inc as well as a methyltransferase, and is only present in Chlamydophila spp. (Kalman et al., 1999). IncD to $\mathbf{G}$ are expressed as an operon in the early stages of the developmental cycle, suggesting an important role in remodeling the nascent chlamydial inclusion. In immunofluorescence studies, patterns for these Incs resemble IncB staining: distinct patches of the inclusion membrane are stained, suggesting regions of close contact between the RB and the inclusion membrane (Scidmore-Carlson et al., 1999). C. trachomatis IncG is normally exposed on the cytoplasmic surface of the inclusion (Hackstadt et al., 1999) and was used as a bait to determine host proteins that interact with the inclusion. The eukaryotic interaction partner was proven to be 14-3-3 $\beta$, a phosphoserinebinding protein involved in several signaling pathways as a scaffold for phosphotransfer. This specific interaction could be confirmed by the demonstration of two specific 14-3-3 $\beta$ binding sites at the carboxy terminal region of IncG, and colocalization studies in cell cultures infected with $C$. trachomatis serovars $A, B, B a, C, D, E, F, G, H$, $\mathrm{I}, \mathrm{J}, \mathrm{K}$ and L1-3. In Cp. pneumoniae, Cp. caviae and C. muridarum infected cells no such interaction could be observed, which is not surprising given the absence of IncG in the first two species and the large sequence difference with $C$. muridarum IncG (Scidmore and Hackstadt, 2001). The inverse approach was followed to identify possible interactions with eukaryotic RabGTPases localized in the inclusion membrane region. In a yeast-2-hybrid screening with Rab4 GTPase as a bait, only CT229 interacted. Furthermore, Rab4 was found to colocalize with CT229 on the inclusion membrane surface, an interaction requiring the presence of a GTP-binding domain (Rzomp et al., 2006). Similarly, Cpn0585 interacts with Rab1, Rab10 and Rab11 (Cortes et al., 2007). CrpA, also known as CT442 in C. trachomatis, is one of the Incs predicted by the study of Bannantine et al. (2000). This protein was erroneously regarded as a cysteine rich protein in the chlamydial outer membrane (Clarke et al., 1988; Lambden et al., 1990 ) but contains only four Cys residues and has been shown to localize to the inclusion membrane by immunochemistry (Bannantine et al., 2000). CrpA is recognized by $\mathrm{CD}^{+}$T-cells, and may have access, together with other Incs, to the class I MHC-processing pathways of infected cells (Starnbach et al., 2003).

Some proteins localized in the inclusion membrane lack the characteristic bilobed hydrophobic domain. Two of them, SctW and Cap1, are proven T3S effector proteins (Fields and Hackstadt, 2000; Subtil et al., 2005). SctW probably acts as a gating protein, preventing or allowing T3S proteins to be translocated across the bacterial membranes, while Cap1 (Class I Accessible Protein-1, CT529) is another $\mathrm{CD}^{+}$T-cell antigen (Fling et al., 2001). This protein is expressed during the early stages of the C. trachomatis developmental cycle and by $8 \mathrm{~h}$ after infection, sufficient Cap1 protein is expressed to stimulate $\mathrm{CD}^{+} \mathrm{T}$ cells. Cap1 may therefore play an important role in early immune recognition of C. trachomatis- infected cells (Balsara et al., 2006). CT147 is transcribed early during the development of C. trachomatis and shows significant homology to EEA1 (mammalian Early Endosomal Antigen 1), involved in trafficking and fusion of mammalian endosomes. Although CT147 lacks homology with the region of EEA1 that has been shown to bind Rab5, it has maintained the carboxy terminal Zn-finger, suggesting CT147 could bind to endosomes but circumvent endosomal fusion, a novel strategy for chlamydial endosomes to avoid fusion with lysosomes (Belland et al., 2003).

The above mentioned results suggest that chlamydial Incs are capable of interfering with vesicle trafficking, guiding inclusion development, avoiding phagolysosomal fusion, acquiring nutrients and diverting important host signaling molecules from their designated pathways. However, there are distinct differences in how chlamydial species interact with intracellular membranes, so caution should be exercised when extrapolating findings to other chlamydial species.

Other secreted T3S effector proteins are summarized in Table 3. These include the Translocated actin recruiting protein Tarp, mediating host cell internalization through the recruitment of actin filaments to the site of chlamydial attachment (see further). CADD (Chlamydia protein associating with death domains) has been shown to be involved in modulation of host cell apoptosis via binding to the death domains of tumor necrosis factor family receptors. This novel redox protein toxin has limited sequence identity with coenzyme PQQ (pyrrolo-quinoline quinone) synthesis protein $\mathrm{C}$ (PqqC) family members, which are part of the six-step $P Q Q$ synthesis pathway in bacteria (Stenner-Liewen et al., 2002; Schwarzenbacher et al., 2004). As already mentioned above, SctP might be a ruler protein involved in determination of the needle length of the T3SS (Stone et al., 2008). Pkn5 was originally annotated as a putative serine/threonine kinase and postulated to be T3SS related when the genome of $C$. trachomatis was sequenced (Stephens et al., 1998). 
Table 3: Overview of chlamydial T3S effector proteins. The corresponding gene number in C. trachomatis or Cp. pneumoniae is given. Legend: IncM, inclusion membrane.

\begin{tabular}{llll}
\hline \hline Effector & Location & Gene number & Possible function \\
\hline Tarp & Surface of EB, host cell cytosol & CT456/Cpn0572 & Invasion, actin recruitment \\
CADD & Proximity of the inclusion & CT610/Cpn0761 & Modulation of host cell apoptosis \\
SctP & Bacteria and host cell cytosol & CT671/Cpn0705 & Putative T3SS needle ruler protein \\
Pkn5 & Inclusion and host cell cytosol & CT673/Cpn0703 & S/T kinase activity \\
Mip & Surface of EB, RB and IncM & CT541/Cpn0661 & Induction of cytokine response \\
Hypothetical & Unknown & CT668/Cpn0708 & Unknown \\
Hypothetical & Bacteria and host cell cytosol & CT694/ absent & Interaction with human AHNAK \\
Hypothetical & Unknown & CT847/Cpn1004 & Interacts with human GCIP \\
\hline \hline
\end{tabular}

Since then, C. trachomatis Pkn5 was proven to be secreted by the heterologous Salmonella SPI-2 T3SS (Ho and Starnbach, 2005) as well as to be secreted into the inclusion membrane of Cp.pneumoniae by Herrmann et al. (2006). The lipoprotein Mip is homologous to the macrophage infectivity potentiator (Mip) gene of L. pneumophila (Lundemose et al., 1993a; 1993b). Localization studies first reported Cp. pneumoniae and Cp. caviae Mip to be surface exposed on EBs and RBs (Rockey et al., 1996; Montigiani et al., 2002). Later on, Herrmann et al. (2006) demonstrated that $\mathrm{Cp}$. pneumoniae secretes Mip into the host cell cytoplasm. They concluded that the substrate proteins of Mip might be other chlamydial proteins/virulence factors in the inclusion membrane or host cell proteins whose conformation might be altered by Mip peptidyl prolyl cis-trans isomerase activity. Genes encoding CT668 and its homologs in other chlamydial species are located in the third T3S gene cluster (

Figure 2), and at least for $C$. trachomatis, this protein has been shown to be Type III secreted (Sisko et al., 2006). No function or cellular localization for this protein has so far been identified. In contrast, CT694 is localized separate from bacteria only in the early phase of infection, and interacts with the repeat region of human AHNAK, presumably leading to Raf/MEK/ERK activation and modulation of the actin cytoskeleton. T3SS dependency was shown by heterologous translocation through the Y. pseudotuberculosis T3SS. As CT694 is only found in $C$. trachomatis, this protein could contribute in aspects unique compared to the other chlamydial species (Hower et al., 2009). CT874, secreted through the heterologous T3SS of $Y$. pseudotuberculosis, interacts in the host cell cytoplasm with a eukaryotic protein termed GCIP (Grap2 cyclin D-interacting protein) a multi-functional ubiquitously expressed protein that is degraded during chlamydial infection (Chellas-Gery et al., 2007).

\section{Role of T3S in the chlamydial lifecycle}

The T3SS plays an essential role throughout the chlamydial developmental cycle. In the following paragraphs, a short description is given of how chlamydiae employ their T3SS to modify the intravacuolar environment to their benefit at different stages in the life cycle.

Differential gene expression - resolving the 'chlamydial Type III paradox'

Upon irreversible attachment to the host cell, EBs directly translocate pre-existing effectors (e.g. Tarp) to the host cell cytosol (Clifton et al., 2005; Jewett et al.,
2006). In addition, expression and secretion of Cp. pneumoniae IncA, IncB and IncC (Lugert et al., 2004) and C. trachomatis IncC (Fields et al., 2003) occurs already within $2 \mathrm{~h}$ (early cycle) post infection. However, expression of T3S-specific Sct-genes is not detectable until 8 to $12 \mathrm{~h}$ post infection, implying that de novo synthesis of T3SSs only appears from mid-cycle onwards (Fields et al., 2003; Lugert et al., 2004).

These observations immediately raised the question how chlamydiae can secrete and translocate their effector molecules early after infection, even before assembly of a functional T3SS. A possible solution for this 'chlamydial Type III paradox' came from studies by Vandahl et al. (2001), Fields et al. (2003) and Lugert et al. (2004), demonstrating the existence of the Type III secretion apparatus on both $C$. trachomatis and Cp. pneumoniae EBs. Proteome analysis of Cp. pneumoniae EBs by Vandahl et al. (2001) revealed that all components of the T3SS are present in EBs. Presence of CopD1 was highly abundant, its chaperone Scc2 being expressed late in the developmental cycle, as is the case for the majority of T3SS structural genes (Slepenkin et al., 2003). The presence of high amounts of CopD1 in purified EBs implied that it had been retained in the bacteria during the late phase of the developmental cycle. They suggested that CopD1 is preloaded in EBs, ready to be secreted by T3S upon contact with a host cell. This hypothesis could be further strengthened by the finding of the other translocon protein CopB1 in the cytoplasm of $\mathrm{Cp}$. pneumoniae infected cells (Lugert et al., 2004). Additional and striking evidence was provided by Fields et al. (2003), demonstrating the existence of a T3S apparatus on EBs by matrix-assisted laser desorption ionization time-offlight (MALDI-TOF) and immunoblotting of purified EB extracts using polyclonal antibodies specific for the studied proteins. Based on their findings Fields et al. (2003) proposed a model in which T3SSs are present on EBs and mediate secretion of effectors such as Tarp and early Incs. Mid-cycle expression of T3S genes would then replenish the secretion apparatuses on RBs and serve as a source of secretion pores for subsequently formed EBs. This was also confirmed by Maurer et al. showing that genes coding for EB proteins were primarily connected with products in late, but not tardy (showing steadily increasing expression at the end of the cycle) expressed gene clusters (Maurer et al., 2007).

As mentioned above, Chlamydiaceae possess two sets of translocators, each with their specific chaperone, needed during different periods of infection and therefore expressed at different time points during the developmental cycle. In C. trachomatis, RT-PCR analysis showed $c o p B 1, c o p D 1$ and $s c c 2$ expression 
from $20 \mathrm{~h}$ post infection onwards (Fields et al., 2003), while expression from $24 \mathrm{~h}$ post infection onwards could be observed in Cp. pneumoniae for scc2 (Slepenkin et al., 2003; Lugert et al., 2004). The second chlamydial translocon cluster (scc3/copB2/copD2) was expressed earlier: from $12 \mathrm{~h}$ post infection in C. trachomatis, and from the earliest studied time point on $(1.5-2 h)$ in Cp. pneumoniae (Slepenkin et al., 2003; Lugert et al., 2004). This is in accordance with CopB2 and CopD2 built into the inclusion membrane to allow cellular reprogramming and CopB1 and CopD1 mediating translocation of proteins during the internalization phase (Ouellette et al., 2005; Hefty and Stephens, 2007).

\section{Adhesion and entry}

Adhesion of chlamydial EBs to the host cell is mediated by a number of possible adhesins such as MOMP (Su et al., 1990), Hsp70 (Raulston et al., 1993), OmcB (Ting et al., 1995; Moelleken and Hegemann, 2008) and pmpD (Wehrl et al., 2004; Crane et al., 2006) Analogous to what is described for Shigella flexneri, T3SS translocon components could be involved as well in the irreversible attachment of EBs, assuming that CopB1 binds the hyaluronan receptor CD44 in lipid rafts, thereby inducing complete assembly of the T3SS translocon in the eukaryotic membrane, followed by an interaction of the CopB1-D1-LcrV complex with a nearby $\alpha_{5} \beta_{1}$ integrin receptor on the host cell (Watarai et al., 1996; Skoudy et al., 2000).

Translocation of Tarp into the host cell within minutes following attachment induces actin recruitment and the formation of pedestal-like structures beneath the attached EB. At least two accompanying signaling cascades (Arp2/3 dependent or not) have already been described for $C$. trachomatis (Jewett et al., 2006; Lane et al., 2008), apart from other signaling pathways mediating EB internalization, most likely initiated after translocation of additional currently uncharacterized T3SEs.

In addition to microfilament dependent entry through the lipid raft signaling platforms, Chlamydiaceae also employ receptor mediated uptake by clathrin-coated pits. Possible ligands could include surface exposed T3SS components, e.g. the outer membrane secretin SctC or the needle protein SctF.

Inhibition of phagolysosomal fusion

During infection, Chlamydiaceae resist the host cell nonspecific defence system of phagolysosomal fusion. Inhibition of acidification of the inclusion is most likely accompanied by an active modification of the inclusion membrane (Scidmore et al., 2003). Possible candidates are chlamydial Incs involved in preventing fusion between the chlamydial inclusion and lysosomes (Hackstadt et al., 1997; Wyrick, 2000). In Salmonella, binding of SPI-2 T3SE SpiC with mammalian Hook3 disrupts Golgi morphology and alters lysosomal distribution, thus probably preventing phagosomelysosome fusion (Shotland et al., 2003; Bakowski et al., 2008). Likewise, chlamydiae might translocate unknown T3SEs to the host cell cytoplasm as well.

Role of Incs in the subversion of intracellular host cell traffic

Whilst avoiding fusion with lysosomes, the inclusions migrate to the microtubuli organizing centre - Golgi region to fuse with sphingomyelin-containing exocytic vesicles of the host cell. In addition, glycerophospholipids and other lipids can be acquired through fusion with multivesicular bodies (Beatty, 2006) and lipid droplets (Cocchiaro et al., 2008). The Chlamydiaceae thus manage to intercept nutrients and constituent molecules from normal eukaryotic trafficking pathways, mimicking the phospholipid composition of the host cell in which the bacteria are grown (Hatch and McClarty, 1998).

Elucidation on the mechanisms that divert lipids to the vacuole came from the fact that the chlamydial inclusion interacts with RabGTPases, key regulators of host vesicle fusion. For example, the $C$. trachomatis specific CT229 Inc probably recruits Rab4 to the inclusion membrane surface, in an attempt to regulate the intracellular trafficking or fusogenicity with the chlamydial inclusion (Rzomp et al., 2006). Similarly, Cp. pneumoniae Inc Cpn0585 interacts with Rab1, Rab10 and Rab11 and may mediate their recruitment to the Cp.pneumoniae inclusion. The subsequent interactions are dependent on Rabs bound to GTP, suggesting that the inclusion membrane localized Rab proteins are functional (Rzomp et al., 2006; Cortes et al., 2007).

Another important player in the interception of vesicular trafficking might be IncA. In addition to its involvement in the homotypic fusion of $C$. trachomatis inclusions (Hackstadt et al., 1999), IncA eukaryotic SNARE-like motifs may represent a mimicry mechanism to interact with a subset of host SNAREs, leading to the selective recruitment of intracellular compartments around the inclusion (Delevoye et al., 2008).

Proliferation and engaging into late differentiation As it was often observed that RB replication occurs while Chlamydiaceae are in close contact with the inclusion membrane, it was suggested that this juxtaposition could be needed for growth. This contact is thought to be mediated by T3SSs, most likely corresponding to the surface projections previously described by Matsumoto (1982a). Detachment of RBs from the inclusion membrane and coupled T3SS inactivation would constitute the signal for redifferentiation into EBs, the socalled 'contact-dependent development hypothesis' (Hackstadt et al., 1997; Bavoil and Hsia, 1998; Bavoil et al., 2000). Since then mathematical models linking the number of T3S projections and consecutive events during intracellular development in normal and persistent infections have been described (Wilson et al., 2006; Hoare et al., 2008). A schematic diagram is given in Figure 4.

Briefly, upon attachment of EBs, preloaded T3SSs translocate effector proteins into the host cell to promote internalization, survival and differentiation into RBs. Contact between the RBs and the inclusion membrane upregulates T3S gene-expression, leading to a rise in the number of projections per bacterium, and triggers binary fission of RBs. As the RBs replicate, the inclusion expands, reducing the contact area between $\mathrm{RB}$ and the inclusion membrane, and thus T3S activity. When the number of T3SSs in contact with the inclusion membrane drops below a certain threshold, physical detachment coincides with the upregulation of sctW expression, only expressed late in normal RBs. 


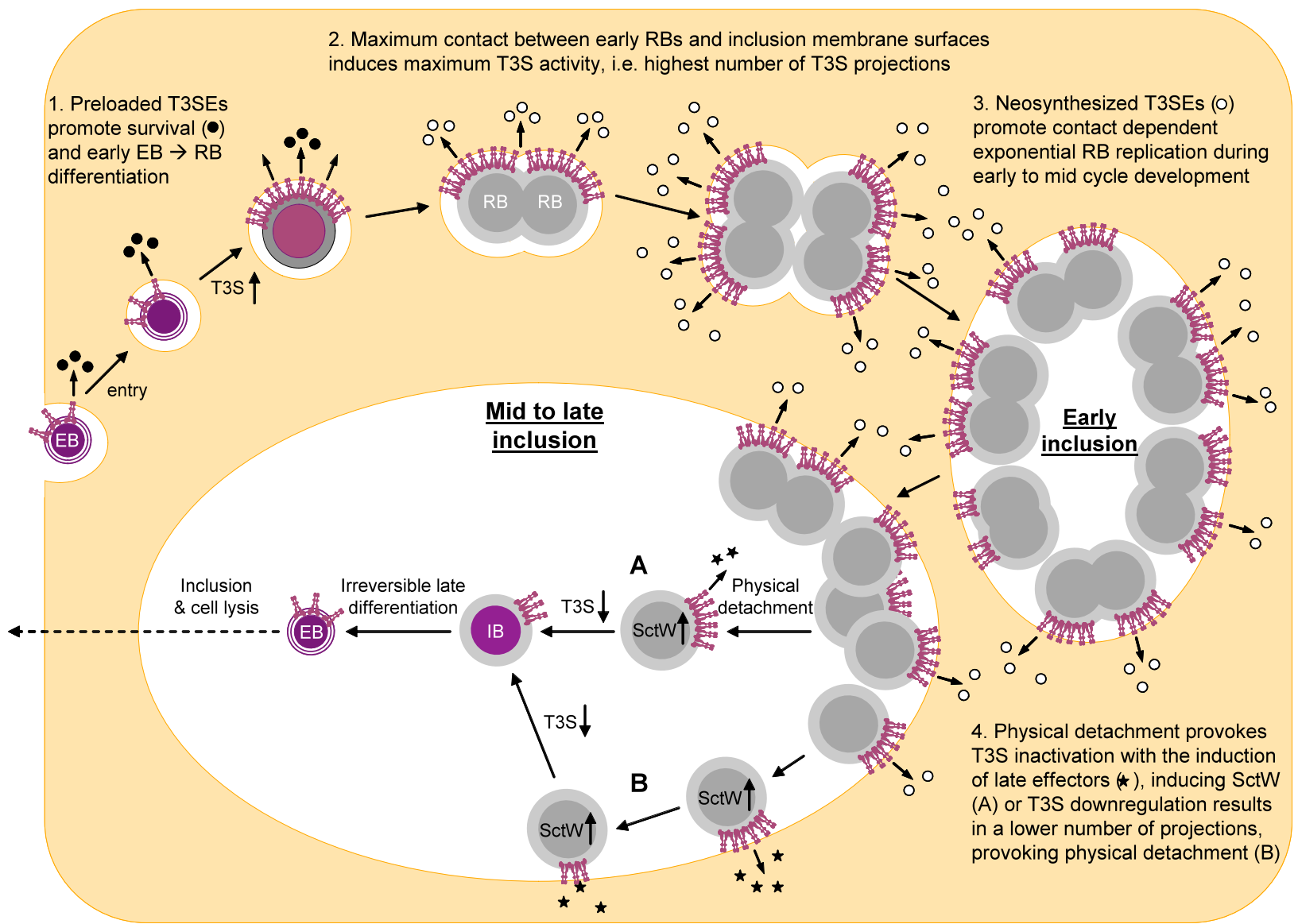

Figure 4: Schematic overview of the contact-dependent chlamydial development hypothesis. Preloaded T3SSs of EBs are implicated in internalization and early survival, while neosynthesized T3SSs promote replication. Adapted from Wilson et al. (2006). IB: intermediate body. Refer to the text for details.

The question then becomes: 1) does overcrowding of the inclusion physically 'squeeze out' RBs to the lumen of the inclusion, thereby inducing SctW expression and downregulation of T3S or rather 2) does the low number of T3SSs per RB shut down T3S through SctW expression, thereby provoking physical detachment? In any case, progressive detachment of bacteria from the inclusion membranes coincides with the observed asynchronicity in the redifferentiation process from RBs to EBs (Wilson et al., 2006; Peters et al., 2007; Hoare et al., 2008).

\section{Acknowledgements}

Delphine S.A. Beeckman is a Post-doctoral Fellow of the Research Foundation - Flanders (FWO - Vlaanderen).

\section{References}

Abraham,S.N., Sun,D., Dale,J.B., and Beachey,E.H. (1988). Conservation of the D-mannose-adhesion protein among type 1 fimbriated members of the family Enterobacteriaceae. Nature 336, 682-684.

Aizawa,S.I. (2001). Bacterial flagella and type III secretion systems. FEMS Microbiol. Lett. 202, 157-164.

Akeda,Y. and Galan,J.E. (2004). Genetic analysis of the Salmonella enterica type III secretion-associated ATPase
InvC defines discrete functional domains. J Bacteriol. 186, 2402-2412.

Akeda,Y. and Galan,J.E. (2005). Chaperone release and unfolding of substrates in type III secretion. Nature 437, 911-915.

Allaoui,A., Sansonetti,P.J., and Parsot,C. (1992). MxiJ, a lipoprotein involved in secretion of Shigella Ipa invasins, is homologous to YscJ, a secretion factor of the Yersinia Yop proteins. J. Bacteriol. 174, 7661-7669.

Allaoui,A., Woestyn,S., Sluiters,C., and Cornelis,G.R. (1994). YscU, a Yersinia enterocolitica inner membrane protein involved in Yop secretion. J. Bacteriol. 176, 4534-4542.

Andersen,C. (2003). Channel-tunnels: outer membrane components of type I secretion systems and multidrug efflux pumps of Gram-negative bacteria. Rev. Physiol Biochem. Pharmacol. 147, 122-165.

Anderson,D.M., Ramamurthi,K.S., Tam,C., and Schneewind,O. (2002). YopD and LcrH regulate expression of Yersinia enterocolitica YopQ by a posttranscriptional mechanism and bind to yopQ RNA. J. Bacteriol. 184, 1287-1295.

Anderson,D.M. and Schneewind,O. (1997). A mRNA signal for the type III secretion of Yop proteins by Yersinia enterocolitica. Science 278, 1140-1143. 
Arnold,R., Brandmaier,S., Kleine,F., Tischler,P., Heinz,E., Behrens,S., Niinikoski,A., Mewes,H.W., Horn,M., and Rattei,T. (2009). Sequence-based prediction of type III secreted proteins. PLoS. Pathog. 5, e1000376.

Averhoff,B. and Friedrich,A. (2003). Type IV pili-related natural transformation systems: DNA transport in mesophilic and thermophilic bacteria. Arch. Microbiol. 180, 385-393.

Azuma,Y., Hirakawa,H., Yamashita,A., Cai,Y., Rahman,M.A., Suzuki,H., Mitaku,S., Toh,H., Goto,S., Murakami,T., Sugi,K., Hayashi,H., Fukushi,H., Hattori,M., Kuhara,S., and Shirai,M. (2006). Genome sequence of the cat pathogen, Chlamydophila felis. DNA Res. 13, 15-23.

Bachmann,J., Bauer,B., Zwicker,K., Ludwig,B., and Anderka,O. (2006). The Rieske protein from Paracoccus denitrificans is inserted into the cytoplasmic membrane by the twin-arginine translocase. FEBS J. 273, 4817-4830.

Backert,S. and Selbach,M. (2008). Role of type IV secretion in Helicobacter pylori pathogenesis. Cell Microbiol. 10, 1573-1581.

Bakowski,M.A., Braun,V., and Brumell,J.H. (2008). Salmonella-Containing Vacuoles: Directing Traffic and Nesting to Grow. Traffic. 9, 2022-2031.

Balsara,Z.R., Roan,N.R., Steele,L.N., and Starnbach,M.N. (2006). Developmental regulation of Chlamydia trachomatis class I accessible protein-1, a CD8+ T cell antigen. J. Infect. Dis. 193, 1459-1463.

Bannantine,J.P., Griffiths,R.S., Viratyosin,W., Brown,W.J., and Rockey,D.D. (2000). A secondary structure motif predictive of protein localization to the chlamydial inclusion membrane. Cell Microbiol. 2, 35-47.

Baron,C. (2005). From bioremediation to biowarfare: on the impact and mechanism of type IV secretion systems. FEMS Microbiol. Lett. 253, 163-170.

Baron,C. (2009). Mechanistic and Structural Analysis of Type IV Secretion Systems. In Bacterial Secreted Proteins: Secretory Mechanisms and Role in Pathogenesis, K.Wooldridge, ed. (Hethersett, Norwich, UK: Caister Academic Press), pp. 117-137.

Bavoil,P.M., Hsia,R., and Ojcius,D.M. (2000). Closing in on Chlamydia and its intracellular bag of tricks. Microbiology 146 ( Pt 11), 2723-2731.

Bavoil,P.M. and Hsia,R.C. (1998). Type III secretion in Chlamydia: a case of deja vu? Mol. Microbiol. 28, 860-862.

Beatty,W.L. (2006). Trafficking from CD63-positive late endocytic multivesicular bodies is essential for intracellular development of Chlamydia trachomatis. J. Cell Sci. 119, 350-359.

Beeckman,D.S., Geens,T., Timmermans,J.-P., Van Oostveldt,P., and Vanrompay,D.C. (2008). Identification and characterization of a type III secretion system in Chlamydophila psittaci. Vet. Res. 39, 27.

Belland,R.J., Zhong,G., $\quad$ Crane,D.D., Hogan,D., Sturdevant,D., Sharma,J., Beatty,W.L., and Caldwell,H.D. (2003). Genomic transcriptional profiling of the developmental cycle of Chlamydia trachomatis. Proc. Natl. Acad. Sci. U. S. A 100, 8478-8483.

Berks,B.C., Sargent,F., and Palmer,T. (2000). The Tat protein export pathway. Mol. Microbiol. 35, 260-274.

Betts,H.J., Twiggs,L.E., Sal,M.S., Wyrick,P.B., and Fields,K.A. (2008). Bioinformatic and biochemical evidence for the identification of the type III secretion system needle protein of Chlamydia trachomatis. J. Bacteriol. 190, 1680-1690.

Bingle,L.E., Bailey,C.M., and Pallen,M.J. (2008). Type VI secretion: a beginner's guide. Curr. Opin. Microbiol. 11, 3-8.

Birtalan,S.C., Phillips,R.M., and Ghosh,P. (2002). Threedimensional secretion signals in chaperone-effector complexes of bacterial pathogens. Mol. Cell 9, 971-980.

Blocker,A.J., Deane,J.E., Veenendaal,A.K., Roversi,P., Hodgkinson,J.L., Johnson,S., and Lea,S.M. (2008). What's the point of the type III secretion system needle? Proc. Natl. Acad. Sci U. S. A 105, 6507-6513.

Brandt,S., Kwok,T., Hartig,R., Konig,W., and Backert,S. (2005). NF-kappaB activation and potentiation of proinflammatory responses by the Helicobacter pylori CagA protein. Proc. Natl. Acad. Sci. U. S. A 102, 9300-9305.

Brito,C.F., Carvalho,C.B., Santos,F., Gazzinelli,R.T., Oliveira,S.C., Azevedo,V., and Teixeira,S.M. (2004). Chromobacterium violaceum genome: molecular mechanisms associated with pathogenicity. Genet. Mol. Res. 3, 148-161.

Broz,P., Mueller,C.A., Muller,S.A., Philippsen,A., Sorg,I., Engel,A., and Cornelis,G.R. (2007). Function and molecular architecture of the Yersinia injectisome tip complex. Mol. Microbiol. 65, 1311-1320.

Burr,S.E., Wahli,T., Segner,H., Pugovkin,D., and Frey,J. (2003). Association of Type III secretion genes with virulence of Aeromonas salmonicida subsp. salmonicida. Dis. Aquat. Organ. 57, 167-171.

Buttner,D. and Bonas,U. (2002). Port of entry - the type III secretion translocon. Trends Microbiol. 10, 186-192.

Buttner,D. and Bonas,U. (2006). Who comes first? How plant pathogenic bacteria orchestrate type III secretion. Curr. Opin. Microbiol. 9, 193-200.

Cascales,E. (2008). The type VI secretion toolkit. EMBO Rep. 9, 735-741.

Chellas-Gery,B., Linton,C.N., and Fields,K.A. (2007). Human GCIP interacts with CT847, a novel Chlamydia trachomatis type III secretion substrate, and is degraded in a tissue-culture infection model. Cell Microbiol. 9, 2417-2430.

Cheng,L.W., Kay,O., and Schneewind,O. (2001). Regulated secretion of YopN by the type III machinery of Yersinia enterocolitica. J. Bacteriol. 183, 5293-5301.

Christie,P.J.,Atmakuri,K., Krishnamoorthy, V., Jakubowski,S., and Cascales,E. (2005). Biogenesis, architecture, and function of bacterial type IV secretion systems. Annu. Rev. Microbiol. 59, 451-485.

Christie,P.J. and Cascales,E. (2005). Structural and dynamic properties of bacterial type IV secretion systems (review). Mol. Membr. Biol. 22, 51-61.

Cianciotto,N.P. (2005). Type II secretion: a protein secretion system for all seasons. Trends Microbiol. 13, 581-588.

Clarke,I.N., Ward,M.E., and Lambden,P.R. (1988). Molecular cloning and sequence analysis of a developmentally regulated cysteine-rich outer membrane protein from Chlamydia trachomatis. Gene 71, 307-314.

Clifton,D.R., Dooley,C.A., Grieshaber,S.S., Carabeo,R.A., Fields,K.A., and Hackstadt,T. (2005). Tyrosine phosphorylation of the chlamydial effector protein Tarp is species specific and not required for recruitment of actin. Infect. Immun. 73, 3860-3868. 
Cocchiaro,J.L., Kumar,Y., Fischer,E.R., Hackstadt,T., and Valdivia,R.H. (2008). Cytoplasmic lipid droplets are translocated into the lumen of the Chlamydia trachomatis parasitophorous vacuole. Proc. Natl. Acad. Sci U. S. A 105, 9379-9384.

Cornelis,G.R. (2000). Type III secretion: a bacterial device for close combat with cells of their eukaryotic host. Philos. Trans. R. Soc. Lond B Biol. Sci. 355, 681-693.

Cornelis,G.R. (2006). The type III secretion injectisome. Nat. Rev. Microbiol. 4, 811-825.

Cornelis,G.R. and Van Gijsegem,F. (2000). Assembly and function of type III secretory systems. Annu. Rev. Microbiol. 54, 735-774.

Cortes,C., Rzomp,K.A., Tvinnereim,A., Scidmore,M.A., and Wizel,B. (2007). Chlamydia pneumoniae inclusion membrane protein Cpn0585 interacts with multiple Rab GTPases. Infect. Immun. 75, 5586-5596.

Crane,D.D., Carlson,J.H., Fischer,E.R., Bavoil,P., Hsia,R.C., Tan,C., Kuo,C.C., and Caldwell,H.D. (2006). Chlamydia trachomatis polymorphic membrane protein $\mathrm{D}$ is a species-common pan-neutralizing antigen. Proc. Natl. Acad. Sci. U. S. A 103, 1894-1899.

Dale,C., Plague, G.R., Wang,B., Ochman,H., and Moran,N.A. (2002). Type III secretion systems and the evolution of mutualistic endosymbiosis. Proc. Natl. Acad. Sci. U. S. A 99, 12397-12402.

Dale,C., Young,S.A., Haydon,D.T., and Welburn,S.C. (2001). The insect endosymbiont Sodalis glossinidius utilizes a type III secretion system for cell invasion. Proc. Natl. Acad. Sci. U. S. A 98, 1883-1888.

Darwin,K.H. and Miller,V.L. (2000). The putative invasion protein chaperone SicA acts together with InvF to activate the expression of Salmonella typhimurium virulence genes. Mol. Microbiol. 35, 949-960.

Das,S. and Chaudhuri,K. (2003). Identification of a unique IAHP (IcmF associated homologous proteins) cluster in Vibrio cholerae and other proteobacteria through in silico analysis. In Silico. Biol. 3, 287-300.

De Buck,E., Vranckx,L., Meyen,E., Maes,L., Vandersmissen,L., Anne,J., and Lammertyn,E. (2007). The twin-arginine translocation pathway is necessary for correct membrane insertion of the Rieske Fe/S protein in Legionella pneumophila. FEBS Lett. 581, 259-264.

Delahay,R.M., Shaw,R.K., Elliott,S.J., Kaper,J.B., Knutton,S., and Frankel,G. (2002). Functional analysis of the enteropathogenic Escherichia coli type III secretion system chaperone CesT identifies domains that mediate substrate interactions. Mol. Microbiol. 43, 61-73.

Delepelaire,P. (2004). Type I secretion in gram-negative bacteria. Biochim. Biophys. Acta 1694, 149-161.

Delevoye,C., Nilges,M., Dautry-Varsat,A., and Subtil,A. (2004). Conservation of the biochemical properties of IncA from Chlamydia trachomatis and Chlamydia caviae: oligomerization of IncA mediates interaction between facing membranes. J. Biol. Chem. 279, 46896-46906.

Delevoye,C., Nilges,M., Dehoux,P., Paumet,F., Perrinet,S., Dautry-Varsat,A., and Subtil,A. (2008). SNARE protein mimicry by an intracellular bacterium. PLoS. Pathog. 4 , e1000022.

Desvaux,M., Khan,A., Beatson,S.A., Scott-Tucker,A., and Henderson,I.R. (2005). Protein secretion systems in Fusobacterium nucleatum: genomic identification of Type 4 piliation and complete Type $\mathrm{V}$ pathways brings new insight into mechanisms of pathogenesis. Biochim. Biophys. Acta 1713, 92-112.

Desvaux,M., Parham,N.J., and Henderson,I.R. (2004a). Type $\mathrm{V}$ protein secretion: simplicity gone awry? Curr. Issues Mol. Biol. 6, 111-124.

Desvaux,M., Parham,N.J., Scott-Tucker,A., and Henderson,I.R. (2004b). The general secretory pathway: a general misnomer? Trends Microbiol. 12, 306-309.

Economou,A., Christie,P.J., Fernandez,R.C., Palmer,T., Plano,G.V., and Pugsley,A.P. (2006). Secretion by numbers: Protein traffic in prokaryotes. Mol. Microbiol. 62, 308-319.

Ferrandez,Y. and Condemine,G. (2008). Novel mechanism of outer membrane targeting of proteins in Gram-negative bacteria. Mol. Microbiol. 69, 1349-1357.

Fields,K.A., Fischer,E., and Hackstadt,T. (2002). Inhibition of fusion of Chlamydia trachomatis inclusions at 32 degrees C correlates with restricted export of IncA. Infect. Immun. 70, 3816-3823.

Fields,K.A., Fischer,E.R., Mead,D.J., and Hackstadt,T. (2005). Analysis of putative Chlamydia trachomatis chaperones Scc2 and Scc3 and their use in the identification of type III secretion substrates. J. Bacteriol. 187, 6466-6478.

Fields,K.A. and Hackstadt,T. (2000). Evidence for the secretion of Chlamydia trachomatis CopN by a type III secretion mechanism. Mol. Microbiol. 38, 1048-1060.

Fields,K.A. and Hackstadt,T. (2002). The chlamydial inclusion: escape from the endocytic pathway. Annu. Rev. Cell Dev. Biol. 18, 221-245.

Fields,K.A. and Hackstadt,T. (2006). The Chlamydia Type III Secretion System: Structure and Implications for Pathogenesis. In Chlamydia: Genomics and Pathogenesis, P.M.Bavoil and P.B.Wyrick, eds. (Wymondham, Norfolk: Horizon Bioscience), pp. 219-233.

Fields,K.A., Mead,D.J., Dooley,C.A., and Hackstadt,T. (2003). Chlamydia trachomatis type III secretion: evidence for a functional apparatus during early-cycle development. Mol. Microbiol. 48, 671-683.

Filloux,A., Hachani,A., and Bleves,S. (2008). The bacterial type VI secretion machine: yet another player for protein transport across membranes. Microbiology 154, 1570-1583.

Fling,S.P., Sutherland,R.A., Steele,L.N., Hess,B., D'Orazio,S.E., Maisonneuve,J., Lampe,M.F., Probst,P., and Starnbach,M.N. (2001). CD8+ T cells recognize an inclusion membrane-associated protein from the vacuolar pathogen Chlamydia trachomatis. Proc. Natl. Acad. Sci. U. S. A 98, 1160-1165.

Forsberg,A., Viitanen,A.M., Skurnik,M., and Wolf-Watz,H. (1991). The surface-located YopN protein is involved in calcium signal transduction in Yersinia pseudotuberculosis. Mol. Microbiol. 5, 977-986.

Galan,J.E. and Wolf-Watz,H. (2006). Protein delivery into eukaryotic cells by type III secretion machines. Nature 444, 567-573.

Genin,S. and Boucher,C.A. (1994). A superfamily of proteins involved in different secretion pathways in gramnegative bacteria: modular structure and specificity of the N-terminal domain. Mol. Gen. Genet. 243, 112-118.

Ghosh,P. (2004). Process of protein transport by the type III secretion system. Microbiol. Mol. Biol. Rev. 68, 771-795.

Gilson,L., Mahanty,H.K., and Kolter,R. (1990). Genetic 
analysis of an MDR-like export system: the secretion of colicin V. EMBO J. 9, 3875-3884.

Gophna,U., Ron,E.Z., and Graur,D. (2003). Bacterial type III secretion systems are ancient and evolved by multiple horizontal-transfer events. Gene 312, 151-163.

Gunasena,D.K., Komrower,J.R., and Maclntyre,S. (2003). The fish pathogen Yersinia ruckeri possesses a TTS system. Adv. Exp. Med. Biol. 529, 105-107.

Gupta,R.S. (2000). The natural evolutionary relationships among prokaryotes. Crit Rev. Microbiol. 26, 111-131.

Hackstadt,T., Fischer,E.R., Scidmore,M.A., Rockey,D.D., and Heinzen,R.A. (1997). Origins and functions of the chlamydial inclusion. Trends Microbiol. 5, 288-293.

Hackstadt,T., Scidmore-Carlson,M.A., Shaw,E.I., and Fischer,E.R. (1999). The Chlamydia trachomatis IncA protein is required for homotypic vesicle fusion. Cell Microbiol. 1, 119-130.

Haller,J.C., Carlson,S., Pederson,K.J., and Pierson,D.E. (2000). A chromosomally encoded type III secretion pathway in Yersinia enterocolitica is important in virulence. Mol. Microbiol. 36, 1436-1446.

Hamad,M.H. and Nilles,M.L. (2007). Roles of YopN, LcrG and LcrV in Controlling Yops Secretion by Yersinia pestis. In The Genus Yersinia - From Genomics to Function, R.D.Perry and J.D.Fetherston, eds. (New York: Springer), pp. 225-234.

Hatch,G.M. and McClarty,G. (1998). Phospholipid composition of purified Chlamydia trachomatis mimics that of the eucaryotic host cell. Infect. Immun. 66, 3727-3735.

Hatch,T.P. (1996). Disulfide cross-linked envelope proteins: the functional equivalent of peptidoglycan in chlamydiae? J. Bacteriol. 178, 1-5.

Hatzixanthis,K., Palmer,T., and Sargent,F. (2003). A subset of bacterial inner membrane proteins integrated by the twin-arginine translocase. Mol. Microbiol. 49, 1377-1390.

Hefty,P.S. and Stephens,R.S. (2007). Chlamydial type III secretion system is encoded on ten operons preceded by sigma 70 -like promoter elements. J. Bacteriol. 189, 198-206.

Henderson,I.R. and Lam,A.C. (2001). Polymorphic proteins of Chlamydia spp.--autotransporters beyond the Proteobacteria. Trends Microbiol. 9, 573-578.

Henderson,I.R., Navarro-Garcia,F., Desvaux,M., Fernandez,R.C., and Ala'Aldeen,D. (2004). Type $V$ protein secretion pathway: the autotransporter story. Microbiol. Mol. Biol. Rev. 68, 692-744.

Hensel,M., Shea,J.E., Gleeson,C., Jones,M.D., Dalton,E., and Holden,D.W. (1995). Simultaneous identification of bacterial virulence genes by negative selection. Science 269, 400-403.

Herrmann,M., Schuhmacher,A., Muhldorfer,I., Melchers,K., Prothmann,C., and Dammeier,S. (2006). Identification and characterization of secreted effector proteins of Chlamydophila pneumoniae TW183. Res. Microbiol. 157, 513-524.

Hinsa,S.M., Espinosa-Urgel,M., Ramos,J.L., and O'Toole,G.A. (2003). Transition from reversible to irreversible attachment during biofilm formation by Pseudomonas fluorescens WCS365 requires an ABC transporter and a large secreted protein. Mol. Microbiol. 49, 905-918.

Ho,T.D. and Starnbach,M.N. (2005). The Salmonella enterica serovar typhimurium-encoded type III secretion systems can translocate Chlamydia trachomatis proteins into the cytosol of host cells. Infect. Immun. 73, 905-911.

Hoare,A., Timms,P., Bavoil,P.M., and Wilson,D.P. (2008). Spatial constraints within the chlamydial host cell inclusion predict interrupted development and persistence. BMC. Microbiol. 8, 5.

Horn,M., Collingro,A., Schmitz-Esser,S., Beier,C.L., Purkhold,U., Fartmann,B., Brandt,P., Nyakatura,G.J., Droege,M., Frishman,D., Rattei,T., Mewes,H.W., and Wagner,M. (2004). Illuminating the evolutionary history of chlamydiae. Science 304, 728-730.

Hower,S., Wolf,K., and Fields,K.A. (2009). Evidence that CT694 is a novel Chlamydia trachomatis T3S substrate capable of functioning during invasion or early cycle development. Mol. Microbiol.

Hsia,R.C., Pannekoek,Y., Ingerowski,E., and Bavoil,P.M. (1997). Type III secretion genes identify a putative virulence locus of Chlamydia. Mol. Microbiol. 25, 351-359.

Hueck,C.J. (1998). Type III protein secretion systems in bacterial pathogens of animals and plants. Microbiol. Mol. Biol. Rev. 62, 379-433.

Ito,K. and Mori,H. (2009). The Sec Protein Secretion System. In Bacterial Secreted Proteins: Secretory Mechanisms and Role in Pathogenesis, K.Wooldridge, ed. (Hethersett, Norwich, UK: Caister Academic Press), pp. 3-22.

Jackson,M.W. and Plano,G.V. (2000). Interactions between type III secretion apparatus components from Yersinia pestis detected using the yeast two-hybrid system. FEMS Microbiol. Lett. 186, 85-90.

Jacob-Dubuisson,F., Locht,C., and Antoine,R. (2001). Two-partner secretion in Gram-negative bacteria: a thrifty, specific pathway for large virulence proteins. Mol. Microbiol. 40, 306-313.

Jamison,W.P. and Hackstadt,T. (2008). Induction of type III secretion by cell-free Chlamydia trachomatis elementary bodies. Microb. Pathog. 45, 435-440.

Jenewein,S., Barry Holland,I., and Schmitt,L. (2009). Type I Bacterial Secretion Systems. In Bacterial Secreted Proteins: Secretory Mechanisms and Role in Pathogenesis , K.Wooldridge, ed. (Hethersett, Norwich, UK: Caister Academic Press), pp. 45-65.

Jewett,T.J., Fischer,E.R., Mead,D.J., and Hackstadt,T. (2006). Chlamydial TARP is a bacterial nucleator of actin. Proc. Natl. Acad. Sci. U. S. A 103, 15599-15604.

Johnson,D.L., Stone,C.B., and Mahony,J.B. (2008). Interactions between CdsD, CdsQ, and CdsL, three putative Chlamydophila pneumoniae type III secretion proteins. J. Bacteriol. 190, 2972-2980.

Journet,L., Agrain,C., Broz,P., and Cornelis,G.R. (2003). The needle length of bacterial injectisomes is determined by a molecular ruler. Science 302, 1757-1760.

Kalman,S., Mitchell,W., Marathe,R., Lammel,C., Fan,J., Hyman,R.W., Olinger,L., Grimwood,J., Davis,R.W., and Stephens,R.S. (1999). Comparative genomes of Chlamydia pneumoniae and C. trachomatis. Nat. Genet. 21, 385-389.

Kim,J.F. (2001). Revisiting the chlamydial type III protein secretion system: clues to the origin of type III protein secretion. Trends Genet. 17, 65-69.

Kleba,B. and Stephens,R.S. (2008). Chlamydial effector proteins localized to the host cell cytoplasmic compartment. Infect. Immun. 76, 4842-4850.

Kostryukova,E.S., Lazarev,V.N., and Govorun,V.M. 
(2008). Inclusion membrane proteins of Chlamydiaceae. Biochemistry (Moscow) Supplemental Series B: Biomedical Chemistry 2, 148-159.

Kubori,T., Matsushima,Y., Nakamura,D., Uralil,J., LaraTejero,M., Sukhan,A., Galan,J.E., and Aizawa,S.I. (1998). Supramolecular structure of the Salmonella typhimurium type III protein secretion system. Science 280, 602-605.

Lambden,P.R., Everson,J.S., Ward,M.E., and Clarke,I.N. (1990). Sulfur-rich proteins of Chlamydia trachomatis: developmentally regulated transcription of polycistronic mRNA from tandem promoters. Gene 87, 105-112.

Lane,B.J., Mutchler,C., Al Khodor,S., Grieshaber,S.S., and Carabeo,R.A. (2008). Chlamydial entry involves TARP binding of guanine nucleotide exchange factors. PLoS. Pathog. 4, e1000014.

Li,Y.F., Poole,S., Rasulova,F., McVeigh,A.L., Savarino,S.J., and Xia,D. (2007). A receptor-binding site as revealed by the crystal structure of $\mathrm{CfaE}$, the colonization factor antigen I fimbrial adhesin of enterotoxigenic Escherichia coli. J. Biol. Chem. 282, 23970-23980.

Lloyd,S.A., Norman,M., Rosqvist,R., and Wolf-Watz,H. (2001). Yersinia YopE is targeted for type III secretion by N-terminal, not mRNA, signals. Mol. Microbiol. 39, 520-531.

Lugert,R., Kuhns,M., Polch,T., and Gross,U. (2004). Expression and localization of type III secretion-related proteins of Chlamydia pneumoniae. Med. Microbiol. Immunol. (Berl) 193, 163-171.

Lundemose,A.G., Kay,J.E., and Pearce,J.H. (1993a). Chlamydia trachomatis Mip-like protein has peptidyl-prolyl cis/trans isomerase activity that is inhibited by FK506 and rapamycin and is implicated in initiation of chlamydial infection. Mol. Microbiol. 7, 777-783.

Lundemose,A.G., Rouch,D.A., Penn,C.W., and Pearce,J.H. (1993b). The Chlamydia trachomatis Mip-like protein is a lipoprotein. J. Bacteriol. 175, 3669-3671.

Macnab,R.M. (1999). The bacterial flagellum: reversible rotary propellor and type III export apparatus. J. Bacteriol. 181, 7149-7153.

Mahfouz,M.E., Grayson,T.H., Dance,D.A., and Gilpin,M.L. (2006). Characterization of the mrgRS locus of the opportunistic pathogen Burkholderia pseudomallei: temperature regulates the expression of a two-component signal transduction system. BMC. Microbiol. 6, 70.

Makino,K., Oshima,K., Kurokawa,K., Yokoyama,K., Uda,T., Tagomori,K., lijima,Y., Najima,M., Nakano,M., Yamashita,A., Kubota,Y., Kimura,S., Yasunaga,T., Honda,T., Shinagawa,H., Hattori,M., and lida,T. (2003a). Genome sequence of Vibrio parahaemolyticus: a pathogenic mechanism distinct from that of $V$ cholerae. Lancet 361, 743-749.

Makino,S., Tobe,T., Asakura,H., Watarai,M., Ikeda,T., Takeshi,K., and Sasakawa,C. (2003b). Distribution of the secondary type III secretion system locus found in enterohemorrhagic Escherichia coli $\mathrm{O} 157: \mathrm{H} 7$ isolates among Shiga toxin-producing E. coli strains. J. Clin. Microbiol. 41, 2341-2347.

Marie,C., Broughton,W.J., and Deakin,W.J. (2001). Rhizobium type III secretion systems: legume charmers or alarmers? Curr. Opin. Plant Biol. 4, 336-342.

Marklund,B.I., Tennent,J.M., Garcia,E., Hamers,A., Baga,M., Lindberg,F., Gaastra,W., and Normark,S. (1992). Horizontal gene transfer of the Escherichia coli pap and prs pili operons as a mechanism for the development of tissue-specific adhesive properties. Mol. Microbiol. 6, 2225-2242.

Matsumoto,A. (1973). Fine structures of cell envelopes of Chlamydia organisms as revealed by freeze-etching and negative staining techniques. J. Bacteriol. 116, 1355-1363.

Matsumoto,A. (1982a). Electron microscopic observations of surface projections on Chlamydia psittaci reticulate bodies. J. Bacteriol. 150, 358-364.

Matsumoto,A. (1982b). Surface projections of Chlamydia psittaci elementary bodies as revealed by freeze-deepetching. J. Bacteriol. 151, 1040-1042.

Matsumoto,A., Fujiwara,E., and Higashi,N. (1976). Observations of the surface projections of infectious small cell of Chlamydia psittaci in thin sections. J. Electron Microsc. (Tokyo) 25, 169-170.

Maurer,A.P., Mehlitz,A., Mollenkopf,H.J., and Meyer,T.F. (2007). Gene expression profiles of Chlamydophila pneumoniae during the developmental cycle and iron depletion-mediated persistence. PLoS. Pathog. 3, e83.

Mavris,M., Page,A.L., Tournebize,R., Demers,B., Sansonetti,P., and Parsot,C. (2002). Regulation of transcription by the activity of the Shigella flexneri type III secretion apparatus. Mol. Microbiol. 43, 1543-1553.

McCann,H.C. and Guttman,D.S. (2008). Evolution of the type III secretion system and its effectors in plant-microbe interactions. New Phytol. 177, 33-47.

Menard,R., Sansonetti,P., Parsot,C., and Vasselon,T. (1994). Extracellular association and cytoplasmic partitioning of the IpaB and IpaC invasins of S. flexneri. Cell 79, 515-525.

Meyer,D., Cunnac,S., Gueneron,M., Declercq,C., Van Gijsegem,F., Lauber,E., Boucher,C., and Arlat,M. (2006). PopF1 and PopF2, two proteins secreted by the type III protein secretion system of Ralstonia solanacearum, are translocators belonging to the HrpF/NopX family. J. Bacteriol. 188, 4903-4917.

Michel,G.P. and Voulhoux,R. (2009). The Type II Secretory System (T2SS) in Gram-negative Bacteria: A Molecular Nanomachine for Secretion of Sec and Tat-Dependent Extracellular Proteins. In Bacterial Secreted Proteins: Secretory Mechanisms and Role in Pathogenesis, K.Wooldridge, ed. (Hethersett, Norwich, UK: Caister Academic Press), pp. 67-92.

Michiels,T. and Cornelis,G.R. (1991). Secretion of hybrid proteins by the Yersinia Yop export system. J. Bacteriol. 173, 1677-1685.

Michiels, T., Wattiau,P., Brasseur,R., Ruysschaert,J.M., and Cornelis, G. (1990). Secretion of Yop proteins by Yersiniae. Infect. Immun. 58, 2840-2849.

Minamino,T., Chu,R., Yamaguchi,S., and Macnab,R.M. (2000). Role of FliJ in flagellar protein export in Salmonella. J. Bacteriol. 182, 4207-4215.

Moelleken,K. and Hegemann,J.H. (2008). The Chlamydia outer membrane protein $\mathrm{OmcB}$ is required for adhesion and exhibits biovar-specific differences in glycosaminoglycan binding. Mol. Microbiol. 67, 403-419.

Montigiani,S., Falugi,F., Scarselli,M., Finco,O., Petracca,R., Galli,G., Mariani,M., Manetti,R., Agnusdei,M., Cevenini,R., Donati,M., Nogarotto,R., Norais,N., Garaguso,I., Nuti,S., Saletti,G., Rosa,D., Ratti,G., and Grandi,G. (2002). Genomic approach for analysis of surface proteins in Chlamydia pneumoniae. Infect. Immun. 70, 368-379. 
Mougous,J.D., Cuff,M.E., Raunser,S., Shen,A., Zhou,M., Gifford,C.A., Goodman,A.L., Joachimiak,G., Ordonez,C.L., Lory,S., Walz,T., Joachimiak,A., and Mekalanos,J.J. (2006). A virulence locus of Pseudomonas aeruginosa encodes a protein secretion apparatus. Science 312, 1526-1530.

Moulder,J.W. (1993). Why is Chlamydia sensitive to penicillin in the absence of peptidoglycan? Infect. Agents Dis. 2, 87-99.

Mueller,C.A., Broz,P., and Cornelis,G.R. (2008). The type III secretion system tip complex and translocon. Mol. Microbiol. 68, 1085-1095.

Muller,S.A., Pozidis,C., Stone,R., Meesters,C., Chami,M., Engel,A., Economou,A., and Stahlberg,H. (2006). Double hexameric ring assembly of the type III protein translocase ATPase HrcN. Mol. Microbiol. 61, 119-125.

Nagai,H., Kagan,J.C., Zhu,X., Kahn,R.A., and Roy,C.R. (2002). A bacterial guanine nucleotide exchange factor activates ARF on Legionella phagosomes. Science 295, 679-682.

Neyt,C. and Cornelis,G.R. (1999). Role of SycD, the chaperone of the Yersinia Yop translocators YopB and YopD. Mol. Microbiol. 31, 143-156.

Nuccio,S.P. and Baumler,A.J. (2007). Evolution of the chaperone/usher assembly pathway: fimbrial classification goes Greek. Microbiol. Mol. Biol. Rev. 71, 551-575.

Ouellette,S.P., AbdelRahman,Y.M., Belland,R.J., and Byrne,G.I. (2005). The Chlamydia pneumoniae type III secretion-related IcrH gene clusters are developmentally expressed operons. J. Bacteriol. 187, 7853-7856.

Page,A.L. and Parsot,C. (2002). Chaperones of the type III secretion pathway: jacks of all trades. Mol. Microbiol. 46, $1-11$.

Pallen,M.J., Beatson,S.A., and Bailey,C.M. (2005). Bioinformatics, genomics and evolution of non-flagellar type-III secretion systems: a Darwinian perspective. FEMS Microbiol. Rev. 29, 201-229.

Pallen,M.J., Chaudhuri,R.R., and Henderson,I.R. (2003a). Genomic analysis of secretion systems. Curr. Opin. Microbiol. 6, 519-527.

Pallen,M.J., Francis,M.S., and Futterer,K. (2003b). Tetratricopeptide-like repeats in type-III-secretion chaperones and regulators. FEMS Microbiol. Lett. 223, 53-60.

Panahandeh,S., Holzapfel,E., and Müller,M. (2009). The Twin-Arginine Translocation Pathway. In Bacterial Secreted Proteins: Secretory Mechanisms and Role in Pathogenesis , K.Wooldridge, ed. (Hethersett, Norwich, UK: Caister Academic Press), pp. 23-43.

Park,K.S., Ono, T., Rokuda,M., Jang,M.H., Okada,K., lida,T., and Honda,T. (2004). Functional characterization of two type III secretion systems of Vibrio parahaemolyticus. Infect. Immun. 72, 6659-6665.

Payne,P.L. and Straley,S.C. (1998). YscO of Yersinia pestis is a mobile core component of the Yop secretion system. J. Bacteriol. 180, 3882-3890.

Peabody,C.R., Chung,Y.J., Yen,M.R., Vidal-Ingigliardi,D., Pugsley,A.P., and Saier,M.H., Jr. (2003). Type II protein secretion and its relationship to bacterial type IV pili and archaeal flagella. Microbiology 149, 3051-3072.

Peters, J., Wilson,D.P., Myers,G., Timms,P., and Bavoil,P.M. (2007). Type III secretion a la Chlamydia. Trends Microbiol. 15, 241-251.
Plano,G.V., Barve,S.S., and Straley,S.C. (1991). LcrD, a membrane-bound regulator of the Yersinia pestis lowcalcium response. J. Bacteriol. 173, 7293-7303.

Plano,G.V., Day,J.B., and Ferracci,F. (2001). Type III export: new uses for an old pathway. Mol. Microbiol. 40, 284-293.

Plano,G.V. and Straley,S.C. (1995). Mutations in yscC, yscD, and yscG prevent high-level expression and secretion of $\mathrm{V}$ antigen and Yops in Yersinia pestis. J. Bacteriol. 177, 3843-3854.

Pohlner,J., Halter,R., Beyreuther,K., and Meyer,T.F. (1987). Gene structure and extracellular secretion of Neisseria gonorrhoeae IgA protease. Nature 325, 458-462.

Pohlschröder,M. and Dilks,K.C. (2007). Protein Translocation into and across Archaeal Cytoplasmic Membranes. In Archaea: Molecular and Cellular Biology, R.Cavicchioli, ed. (Washington, D.C.: ASM Press), pp. 369-384.

Pozidis,C., Chalkiadaki,A., Gomez-Serrano,A., Stahlberg,H., Brown,I., Tampakaki,A.P., Lustig,A., Sianidis,G., Politou,A.S., Engel,A., Panopoulos,N.J., Mansfield,J., Pugsley,A.P., Karamanou,S., and Economou,A. (2003). Type III protein translocase: HrcN is a peripheral ATPase that is activated by oligomerization. J. Biol. Chem. 278, 25816-25824.

Pukatzki,S., Ma,A.T., $\quad$ Sturtevant,D., Krastins,B., Sarracino,D., Nelson,W.C., Heidelberg,J.F., and Mekalanos,J.J. (2006). Identification of a conserved bacterial protein secretion system in Vibrio cholerae using the Dictyostelium host model system. Proc. Natl. Acad. Sci. U. S. A 103, 1528-1533.

Rainbow,L., Hart,C.A., and Winstanley,C. (2002). Distribution of type III secretion gene clusters in Burkholderia pseudomallei, B. thailandensis and B. mallei. J. Med. Microbiol. 51, 374-384.

Ramamurthi,K.S. and Schneewind,O. (2002). Type III protein secretion in yersinia species. Annu. Rev. Cell Dev. Biol. 18, 107-133.

Rambow-Larsen,A.A. and Weiss,A.A. (2004). Temporal expression of pertussis toxin and Ptl secretion proteins by Bordetella pertussis. J. Bacteriol. 186, 43-50.

Raulston,J.E., Davis,C.H., Schmiel,D.H., Morgan,M.W., and Wyrick,P.B. (1993). Molecular characterization and outer membrane association of a Chlamydia trachomatis protein related to the hsp70 family of proteins. J. Biol. Chem. 268, 23139-23147.

Read,T.D.,Brunham,R.C., Shen,C., Gill,S.R., Heidelberg,J.F., White,O., Hickey,E.K., Peterson,J., Utterback, T., Berry,K., Bass,S., Linher,K., Weidman,J., Khouri,H., Craven,B., Bowman,C., Dodson,R., Gwinn,M., Nelson,W., DeBoy,R., Kolonay,J., McClarty,G., Salzberg,S.L., Eisen,J., and Fraser,C.M. (2000). Genome sequences of Chlamydia trachomatis MoPn and Chlamydia pneumoniae AR39. Nucleic Acids Res. 28, 1397-1406.

Read,T.D., Myers,G.S., Brunham,R.C., Nelson,W.C., Paulsen,I.T., Heidelberg,J., Holtzapple,E., Khouri,H., Federova,N.B., Carty,H.A., Umayam,L.A., Haft,D.H., Peterson,J., Beanan,M.J., White,O., Salzberg,S.L., Hsia,R.C., McClarty,G., Rank,R.G., Bavoil,P.M., and Fraser,C.M. (2003). Genome sequence of Chlamydophila caviae (Chlamydia psittaci GPIC): examining the role of niche-specific genes in the evolution of the Chlamydiaceae. Nucleic Acids Res. 31, 2134-2147. 
Ren,C.P., $\quad$ Chaudhuri,R.R., $\quad$ Fivian,A., Bailey,C.M., Antonio,M., Barnes,W.M., and Pallen,M.J. (2004). The ETT2 Gene Cluster, Encoding a Second Type III Secretion System from Escherichia coli, Is Present in the Majority of Strains but Has Undergone Widespread Mutational Attrition. J. Bacteriol. 186, 3547-3560.

Rockey,D.D., Chesebro,B.B., Heinzen,R.A., and Hackstadt,T. (1996). A 28 kDa major immunogen of Chlamydia psittaci shares identity with Mip proteins of Legionella spp. and Chlamydia trachomatis-cloning and characterization of the C. psittaci mip-like gene. Microbiology 142 ( Pt 4), 945-953.

Rockey,D.D., Grosenbach,D., Hruby,D.E., Peacock,M.G., Heinzen,R.A., and Hackstadt, T. (1997). Chlamydia psittaci IncA is phosphorylated by the host cell and is exposed on the cytoplasmic face of the developing inclusion. Mol. Microbiol. 24, 217-228.

Rockey,D.D., $\quad$ Scidmore,M.A., Bannantine,J.P., $\quad$ and Brown,W.J. (2002). Proteins in the chlamydial inclusion membrane. Microbes. Infect. 4, 333-340.

Rusch,S.L. and Kendall,D.A. (2007). Interactions that drive Sec-dependent bacterial protein transport. Biochemistry 46, 9665-9673.

Rzomp,K.A., Moorhead,A.R., and Scidmore,M.A. (2006). The GTPase Rab4 interacts with Chlamydia trachomatis inclusion membrane protein CT229. Infect. Immun. 74, 5362-5373.

Sargent,F., Bogsch,E.G., Stanley,N.R., Wexler,M., Robinson,C., Berks,B.C., and Palmer,T. (1998). Overlapping functions of components of a bacterial Sec-independent protein export pathway. EMBO J. 17, 3640-3650.

Schlumberger,M.C. and Hardt,W.D. (2006). Salmonella type III secretion effectors: pulling the host cell's strings. Curr. Opin. Microbiol. 9, 46-54.

Schwarzenbacher,R., Stenner-Liewen,F., Liewen, H., Robinson,H., Yuan,H., Bossy-Wetzel,E., Reed,J.C., and Liddington,R.C. (2004). Structure of the Chlamydia protein CADD reveals a redox enzyme that modulates host cell apoptosis. J. Biol. Chem. 279, 29320-29324.

Scidmore,M.A., Fischer,E.R., and Hackstadt,T. (2003). Restricted fusion of Chlamydia trachomatis vesicles with endocytic compartments during the initial stages of infection. Infect. Immun. 71, 973-984.

Scidmore,M.A. and Hackstadt,T. (2001). Mammalian 14-3-3beta associates with the Chlamydia trachomatis inclusion membrane via its interaction with IncG. Mol. Microbiol. 39, 1638-1650.

Scidmore-Carlson,M.A., Shaw,E.I., Dooley,C.A., Fischer,E.R., and Hackstadt,T. (1999). Identification and characterization of a Chlamydia trachomatis early operon encoding four novel inclusion membrane proteins. Mol. Microbiol. 33, 753-765.

Scott-Tucker,A. and Henderson,I.R. (2009). Type V Secretion. In Bacterial Secreted Proteins: Secretory Mechanisms and Role in Pathogenesis , K.Wooldridge, ed. (Hethersett, Norwich, UK: Caister Academic Press), pp. 139-157.

Settles,A.M., Yonetani,A., Baron,A., Bush,D.R., Cline,K., and Martienssen,R. (1997). Sec-independent protein translocation by the maize Hcf106 protein. Science 278 , 1467-1470.
Shirai,M., Hirakawa,H., Kimoto,M., Tabuchi,M., Kishi,F., Ouchi,K., Shiba,T., Ishii,K., Hattori,M., Kuhara,S., and Nakazawa,T. (2000). Comparison of whole genome sequences of Chlamydia pneumoniae J138 from Japan and CWL029 from USA. Nucleic Acids Res. 28, 2311-2314.

Shotland,Y., Kramer,H., and Groisman,E.A. (2003). The Salmonella SpiC protein targets the mammalian Hook3 protein function to alter cellular trafficking. Mol. Microbiol. 49, 1565-1576.

Sisko,J.L., Spaeth,K., Kumar,Y., and Valdivia,R.H. (2006). Multifunctional analysis of Chlamydia-specific genes in a yeast expression system. Mol. Microbiol. 60, 51-66.

Skoudy,A., Mounier,J., Aruffo,A., Ohayon,H., Gounon,P., Sansonetti,P., and Tran,V.N. (2000). CD44 binds to the Shigella IpaB protein and participates in bacterial invasion of epithelial cells. Cell Microbiol. 2, 19-33.

Slepenkin,A., de la Maza,L.M., and Peterson,E.M. (2005). Interaction between Components of the Type III Secretion System of Chlamydiaceae. J. Bacteriol. 187, 473-479.

Slepenkin,A., Motin,V., de la Maza,L.M., and Peterson,E.M. (2003). Temporal expression of type III secretion genes of Chlamydia pneumoniae. Infect. Immun. 71, 2555-2562.

Sorg,I. and Cornelis,G. (2009). The Type III Secretion System. In Bacterial Secreted Proteins: Secretory Mechanisms and Role in Pathogenesis, K.Wooldridge, ed. (Hethersett, Norwich, UK: Caister Academic Press), pp. 93-116.

Sorg,I., Wagner,S., Amstutz,M., Muller,S.A., Broz,P., Lussi,Y., Engel,A., and Cornelis,G.R. (2007). YscU recognizes translocators as export substrates of the Yersinia injectisome. EMBO J. 26, 3015-3024.

Starnbach,M.N., Loomis,W.P., Ovendale,P., Regan,D., Hess,B., Alderson,M.R., and Fling,S.P. (2003). An inclusion membrane protein from Chlamydia trachomatis enters the MHC class I pathway and stimulates a CD8+ T cell response. J. Immunol. 171, 4742-4749.

Stenner-Liewen,F., Liewen,H., Zapata,J.M., Pawlowski,K., Godzik,A., and Reed,J.C. (2002). CADD, a Chlamydia protein that interacts with death receptors. J. Biol. Chem. 277, 9633-9636.

Stephens,R.S. (1992). Challenge of Chlamydia research. Infect. Agents Dis. 1, 279-293.

Stephens,R.S., Kalman,S., Lammel,C., Fan,J., Marathe,R., Aravind,L., Mitchell,W., Olinger,L., Tatusov,R.L., Zhao,Q., Koonin,E.V., and Davis,R.W. (1998). Genome sequence of an obligate intracellular pathogen of humans: Chlamydia trachomatis. Science 282, 754-759.

Stephenson,K. (2005). Sec-dependent protein translocation across biological membranes: evolutionary conservation of an essential protein transport pathway (review). Mol. Membr. Biol. 22, 17-28.

Stevens,M.P., Wood,M.W., Taylor,L.A., Monaghan,P., Hawes,P., Jones,P.W., Wallis, T.S., and Galyov,E.E. (2002). An Inv/Mxi-Spa-like type III protein secretion system in Burkholderia pseudomallei modulates intracellular behaviour of the pathogen. Mol. Microbiol. 46, 649-659.

Stone,C.B., Johnson,D.L., Bulir,D.C., Gilchrist,J.D., and Mahony,J.B. (2008). Characterization of the putative type III secretion ATPase CdsN (Cpn0707) of Chlamydophila pneumoniae. J. Bacteriol. 190, 6580-6588.

Su,H., Watkins,N.G., Zhang,Y.X., and Caldwell,H.D. (1990). Chlamydia trachomatis-host cell interactions: role of the 
chlamydial major outer membrane protein as an adhesin. Infect. Immun. 58, 1017-1025.

Subtil,A., Blocker,A., and Dautry-Varsat,A. (2000). Type III secretion system in Chlamydia species: identified members and candidates. Microbes. Infect. 2, 367-369.

Subtil,A., Delevoye,C., Balana,M.E., Tastevin,L., Perrinet,S., and Dautry-Varsat,A. (2005). A directed screen for chlamydial proteins secreted by a type III mechanism identifies a translocated protein and numerous other new candidates. Mol. Microbiol. 56, 1636-1647.

Subtil,A., Parsot,C., and Dautry-Varsat,A. (2001). Secretion of predicted Inc proteins of Chlamydia pneumoniae by a heterologous type III machinery. Mol. Microbiol. 39, 792-800.

Tan,C., Spitznagel,J.K., Shou,H., Hsia,R., and Bavoil,P.M. (2006). The Polymorphic Membrane Protein Gene Family of the Chlamydiaceae. In Chlamydia: Genomics and Pathogenesis, P.M.Bavoil and P.B.Wyrick, eds. (Wymondham, Norfolk: Horizon Bioscience), pp. 195-218.

Tanzer,R.J., Longbottom,D., and Hatch,T.P. (2001). Identification of polymorphic outer membrane proteins of Chlamydia psittaci 6BC. Infect. Immun. 69, 2428-2434.

Thanassi,D.G., Chapman,M.R., and Chakraborty,S. (2009). Assembly and Secretion of Surface Fibres in Gram-negative Bacteria. In Bacterial Secreted Proteins: Secretory Mechanisms and Role in Pathogenesis, K.Wooldridge, ed. (Hethersett, Norwich, UK: Caister Academic Press), pp. 159-192.

Thanassi,D.G. and Hultgren,S.J. (2000). Multiple pathways allow protein secretion across the bacterial outer membrane. Curr. Opin. Cell Biol. 12, 420-430.

Thanassi,D.G., Saulino,E.T., and Hultgren,S.J. (1998). The chaperone/usher pathway: a major terminal branch of the general secretory pathway. Curr. Opin. Microbiol. 1, 223-231.

Thanassi,D.G., Stathopoulos,C., Karkal,A., and Li,H. (2005). Protein secretion in the absence of ATP: the autotransporter, two-partner secretion and chaperone/ usher pathways of gram-negative bacteria (review). Mol. Membr. Biol. 22, 63-72.

Thomson,N.R., Yeats, C., Bell,K., Holden,M.T., Bentley,S.D., Livingstone,M., Cerdeno-Tarraga,A.M., Harris,B., Doggett,J., Ormond,D., Mungall,K., Clarke,K., Feltwell,T., Hance,Z., Sanders,M., Quail,M.A., Price,C., Barrell,B.G., Parkhill,J., and Longbottom,D. (2005). The Chlamydophila abortus genome sequence reveals an array of variable proteins that contribute to interspecies variation. Genome Res. 15, 629-640.

Ting,L.M., Hsia,R.C., Haidaris,C.G., and Bavoil,P.M. (1995). Interaction of outer envelope proteins of Chlamydia psittaci GPIC with the HeLa cell surface. Infect. Immun. 63, 3600-3608.

Troisfontaines,P. and Cornelis,G.R. (2005). Type III secretion: more systems than you think. Physiology (Bethesda) 20, 326-339.

Van Loock,M., Vanrompay,D., Herrmann,B., Vander,S.J., Volckaert,G., Goddeeris,B.M., and Everett,K.D. (2003). Missing links in the divergence of Chlamydophila abortus from Chlamydophila psittaci. Int. J. Syst. Evol. Microbiol. $53,761-770$.
Vandahl,B.B., Birkelund,S., Demol,H., Hoorelbeke,B., Christiansen,G., Vandekerckhove,J., and Gevaert,K. (2001). Proteome analysis of the Chlamydia pneumoniae elementary body. Electrophoresis 22, 1204-1223.

Viitanen,A.M., Toivanen,P., and Skurnik,M. (1990). The IcrE gene is part of an operon in the Icr region of Yersinia enterocolitica 0:3. J. Bacteriol. 172, 3152-3162.

Walker,J.E., Saraste,M., Runswick,M.J., and Gay,N.J. (1982). Distantly related sequences in the alpha- and beta-subunits of ATP synthase, myosin, kinases and other ATP-requiring enzymes and a common nucleotide binding fold. EMBO J. 1, 945-951.

Watarai,M., Funato,S., and Sasakawa,C. (1996). Interaction of Ipa proteins of Shigella flexneri with $\alpha 5 \beta 1$ integrin promotes entry of the bacteria into mammalian cells. J. Exp. Med. 183, 991-999.

Wattiau,P., Bernier,B., Deslee,P., Michiels,T., and Cornelis,G.R. (1994). Individual chaperones required for Yop secretion by Yersinia. Proc. Natl. Acad. Sci. U. S. A 91, 10493-10497.

Wehrl,W., Brinkmann,V., Jungblut,P.R., Meyer,T.F., and Szczepek,A.J. (2004). From the inside out - processing of the Chlamydial autotransporter PmpD and its role in bacterial adhesion and activation of human host cells. Mol. Microbiol. 51, 319-334.

Wilharm,G., Dittmann,S., Schmid,A., and Heesemann,J. (2007). On the role of specific chaperones, the specific ATPase, and the proton motive force in type III secretion. Int. J. Med. Microbiol. 297, 27-36.

Wilson,D.P., Timms,P., McElwain,D.L., and Bavoil,P.M. (2006). Type III secretion, contact-dependent model for the intracellular development of Chlamydia. Bull. Math. Biol. 68, 161-178.

Winstanley,C. and Hart,C.A. (2001). Type III secretion systems and pathogenicity islands. J. Med. Microbiol. 50, 116-126.

Woestyn,S., Allaoui,A., Wattiau,P., and Cornelis,G.R. (1994). YscN, the putative energizer of the Yersinia Yop secretion machinery. J. Bacteriol. 176, 1561-1569.

Wu,L.F., Ize,B., Chanal,A., Quentin,Y., and Fichant,G. (2000). Bacterial twin-arginine signal peptide-dependent protein translocation pathway: evolution and mechanism. J. Mol. Microbiol. Biotechnol. 2, 179-189.

Wyrick,P.B. (2000). Intracellular survival by Chlamydia. Cell Microbiol. 2, 275-282.

Yip,C.K., Finlay,B.B., and Strynadka,N.C. (2005). Structural characterization of a type III secretion system filament protein in complex with its chaperone. Nat. Struct. Mol. Biol. 12, 75-81.

Yoshida,M., Allison,W.S., Esch,F.S., and Futai,M. (1982). The specificity of carboxyl group modification during the inactivation of the Escherichia coli F1-ATPase with dicyclohexyl[14C]carbodiimide. J. Biol. Chem. 257, 10033-10037.

Young,B.M. and Young,G.M. (2002). Evidence for targeting of Yop effectors by the chromosomally encoded Ysa type III secretion system of Yersinia enterocolitica. J. Bacteriol. 184, 5563-5571. 


\section{Further Reading}

Caister Academic Press is a leading academic publisher of advanced texts in microbiology, molecular biology and medical research. Full details of all our publications at caister.com

- MALDI-TOF Mass Spectrometry in Microbiology Edited by: M Kostrzewa, S Schubert (2016) www.caister.com/malditof

- Aspergillus and Penicillium in the Post-genomic Era Edited by: RP Vries, IB Gelber, MR Andersen (2016) www.caister.com/aspergillus2

- The Bacteriocins: Current Knowledge and Future Prospects Edited by: RL Dorit, SM Roy, MA Riley (2016)

www.caister.com/bacteriocins

- Omics in Plant Disease Resistance Edited by: V Bhadauria (2016) www.caister.com/opd

- Acidophiles: Life in Extremely Acidic Environments Edited by: R Quatrini, DB Johnson (2016) www.caister.com/acidophiles

- Climate Change and Microbial Ecology: Current Research and Future Trend

Edited by: J Marxsen (2016)

www.caister.com/climate

- Biofilms in Bioremediation: Current Research and Emerging Technologies

Edited by: G Lear (2016)

www.caister.com/biorem

- Microalgae: Current Research and Applications Edited by: MN Tsaloglou (2016) www.caister.com/microalgae

- Gas Plasma Sterilization in Microbiology: Theory, Applications, Pitfalls and New Perspectives Edited by: H Shintani, A Sakudo (2016) www.caister.com/gasplasma

- Virus Evolution: Current Research and Future Directions Edited by: SC Weaver, M Denison, M Roossinck, et al. (2016) www.caister.com/virusevol

- Arboviruses: Molecular Biology, Evolution and Control Edited by: N Vasilakis, DJ Gubler (2016) www.caister.com/arbo

- Shigella: Molecular and Cellular Biology Edited by: WD Picking, WL Picking (2016) www.caister.com/shigella

-Aquatic Biofilms: Ecology, Water Quality and Wastewater Treatment

Edited by: AM Romaní, H Guasch, MD Balaguer (2016)

www.caister.com/aquaticbiofilms

- Alphaviruses: Current Biology

Edited by: S Mahalingam, L Herrero, B Herring (2016)

www.caister.com/alpha

- Thermophilic Microorganisms

Edited by: F Li (2015)

www.caister.com/thermophile
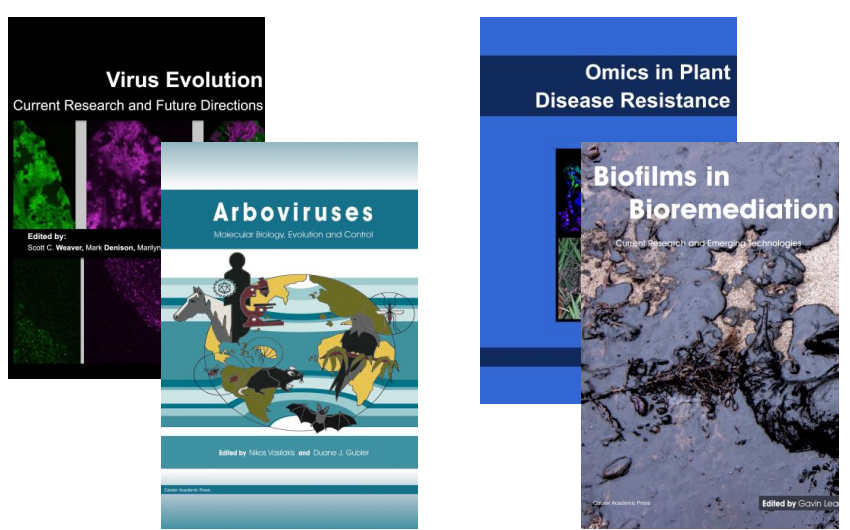
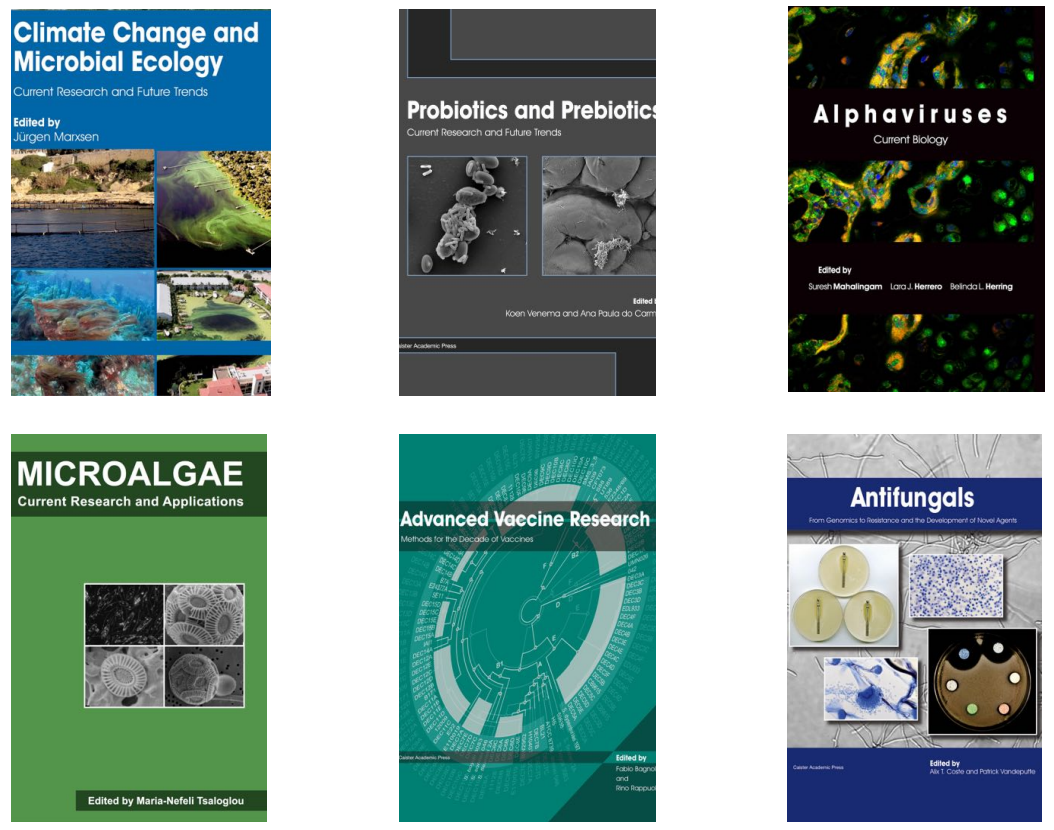

- Flow Cytometry in Microbiology: Technology and Applications Edited by: MG Wilkinson (2015) www.caister.com/flow

- Probiotics and Prebiotics: Current Research and Future Trends Edited by: K Venema, AP Carmo (2015) www.caister.com/probiotics

- Epigenetics: Current Research and Emerging Trends Edited by: BP Chadwick (2015) www.caister.com/epigenetics2015

- Corynebacterium glutamicum: From Systems Biology to Biotechnological Applications

Edited by: A Burkovski (2015)

www.caister.com/cory2

- Advanced Vaccine Research Methods for the Decade of Vaccines

Edited by: F Bagnoli, R Rappuoli (2015)

www.caister.com/vaccines

- Antifungals: From Genomics to Resistance and the Development of Novel Agents

Edited by: AT Coste, P Vandeputte (2015)

www.caister.com/antifungals

- Bacteria-Plant Interactions: Advanced Research and Future Trends Edited by: J Murillo, BA Vinatzer, RW Jackson, et al. (2015) www.caister.com/bacteria-plant

\section{- Aeromonas}

Edited by: J Graf (2015)

www.caister.com/aeromonas

- Antibiotics: Current Innovations and Future Trends

Edited by: S Sánchez, AL Demain (2015)

www.caister.com/antibiotics

- Leishmania: Current Biology and Contro Edited by: S Adak, R Datta (2015) www.caister.com/leish2

- Acanthamoeba: Biology and Pathogenesis (2nd edition) Author: NA Khan (2015)

www.caister.com/acanthamoeba2

- Microarrays: Current Technology, Innovations and Applications Edited by: Z He (2014)

www.caister.com/microarrays2

- Metagenomics of the Microbial Nitrogen Cycle: Theory, Methods and Applications

Edited by: D Marco (2014)

www.caister.com/n2 